Check for updates

Cite this: RSC Adv., 2019, 9, 23864

Received 17th May 2019

Accepted 16th July 2019

DOI: $10.1039 / c 9 r a 03723 c$

rsc.li/rsc-advances

\section{Controlling the product selectivity in the conversion of methanol to the feedstock for phenol production $\uparrow$}

\author{
Abhay Suresh Zambare, D John Ou, David Shan Hill Wong, Ching-Wen Yao \\ and Shi-Shang Jang $\mathbb{D}$ *
}

\begin{abstract}
This work investigated a novel nonpetroleum-based catalytic process of methanol to phenol. The idea was to convert methanol to produce a main product stream having a molar ratio of propylene to benzene/toluene of unity along with relatively higher-value products including para-xylene and alkenes. Such a product mix would be ideal for the manufacturing of phenol. This was achieved using a catalyst of 1.5 wt $\%$ zinc impregnated on a silica-deposited HZSM-5 zeolite at $0.1 \mathrm{MPa}, 430{ }^{\circ} \mathrm{C}$ and $1.2 \mathrm{~h}^{-1}$ weight hourly space velocity. HZSM-5, with its acidic sites predominately being Brønsted acid, produced mainly alkanes and aromatics, of which a good fraction was undesirable nine- or more-nine-carbon higher aromatics. Silica deposition on HZSM-5 passivated the catalytic activity outside the HZSM-5 pores, resulting in an increase of alkenes selectivity, a sharp decrease of nine- or more-nine-carbon higher aromatics selectivity, and a shift of the xylene product from an equilibrium mixture of meta-xylene, para-xylene, and ortho-xylene to mostly para-xylene. Impregnation of 1.5 wt\% zinc on silica-deposited HZSM-5 generated more Lewis acid sites and further increased alkene selectivity, which, with the proper selection of process conditions, led to the production of the target stream. A detailed analysis of the effects of silica deposition, zinc impregnation, acidic sites, and process conditions on the catalyst performance was presented.
\end{abstract}

\section{Introduction}

The objective of this work was to demonstrate a novel nonpetroleum route for methanol to phenol. Phenol is an important chemical feedstock for the production of phenolic resins, synthesis of adipic acid, bisphenol, chloro- and nitrophenols, caprolactam phenol sulfonic acids, etc. Cumene production, which is the first step of phenol production requires a propylene (P) to benzene (B) molar ratio of approximately one. ${ }^{1}$ The idea was to convert methanol to a product having a molar ratio of $\mathrm{P}$ to $\mathrm{B}$ and toluene ( $\mathrm{T}$ ) of unity, along with such valuable byproducts as para-xylene ( $p$-X) and alkenes (ethylene, $\mathrm{P}$, and butenes). As the chemical industry often converts $\mathrm{T}$ to $\mathrm{B}$, such a product would be ideal for the manufacturing of phenol.

Many studies have been carried out for the conversion for methanol to aromatics (MTA) by adding metal species such as zinc, ${ }^{2,3}$ silver, ${ }^{4}$ gallium, ${ }^{5}$ nickel, ${ }^{6,7}$ etc. on HZSM-5. Among all the metal species, zinc has received considerable attention due to its good selectivity toward aromatics, relatively low cost, and being less toxic. ${ }^{8-15}$ In the appendix, Table 7 lists the catalytic performances of HZSM-5, zinc-impregnated HZSM-5 (Zn/

Department of Chemical Engineering, National Tsing Hua University, Hsinchu Taiwan, Republic of China. E-mail: ssjang@mx.nthu.edu.tw; Tel: +886-3-573-5294 $\dagger$ Electronic supplementary information (ESI) available. See DOI: $10.1039 / \mathrm{c} 9 \mathrm{ra} 03723 \mathrm{c}$
HZSM-5), silica-deposited HZSM-5 (Si/HZSM-5), and zincimpregnated silica deposited HZSM-5 (Zn/Si/HZSM-5) found in the literatures. The impregnation of Zn on HZSM-5 in general increased aromatics selectivity and decreased alkanes (methane, ethane, propane, butanes) selectivity. However, the effects of adding $\mathrm{Zn}$ on alkenes and $\mathrm{P}$ selectivities were much less certain and were different in different studies. For example, Zhang et al. ${ }^{9}$ and $\mathrm{Xu}$ et al. ${ }^{\mathbf{1 0}}$ observed an increase in alkenes selectivity. Conte et al. ${ }^{\mathbf{1 1}}$ observed a significant decrease in alkenes selectivity while $\mathrm{Li}$ et $a$ al. $^{\mathbf{1 3}}$ saw a small reduction in alkenes selectivity. With regard to the $p$-X byproduct, on all $\mathrm{Zn}$ modified HZSM-5 catalysts, the purity of $p$-X in xylenes $(p-\mathrm{X} / \mathrm{X})$ was around $24.0 \%$ except for the $72.4 \%$ by Xu et al. ${ }^{10}$

Silica deposition on HZSM-5 would shift the undesirable $m$-X, $o$-X, and nine- or more-nine-carbon higher aromatics (A9+) to the more desirable $p$-X, as shown in the appendix, Table 7. However, changes in the selectivities for alkanes, alkenes, and $\mathrm{P}$ were quite different in these studies. ${ }^{\mathbf{1 3 , 1 6}}$ The alkenes selectivity was very high on Li et al. catalyst. ${ }^{16}$ The discrepancy could be due to the differences in catalysts (e.g. $\mathrm{SiO}_{2} / \mathrm{Al}_{2} \mathrm{O}_{3}$ of 30 (ref. 13) vs. 50, 200 (ref. 16)) and/or reaction temperatures (460 (ref. 13) vs. $400{ }^{\circ} \mathrm{C}$ (ref. 16)).

There were only a few published results on $\mathrm{Zn} / \mathrm{Si} / \mathrm{HZSM}$ 5. ${ }^{12-14}$ Only Li et al. ${ }^{13}$ reported the selectivities of alkenes and aromatics. They observed a substantial increase in the combined selectivity for $\mathrm{B}, \mathrm{T}$, and $p$-X. However, alkenes selectivity decreased marginally. 
Throughout the literatures on methanol conversion, none of the authors reported P/BT molar ratio. We have calculated their molar ratios based on available data shown in Table 7 . The values range from 0.2 to 4.4 . Xu et al. ${ }^{10}$ and Conte et al. ${ }^{11}$ reported $\mathrm{P} / \mathrm{BT}$ molar ratio of 0.9 and 1.4 respectively, which are closest to our objective. However, the selectivities of $\mathrm{P}, \mathrm{B}$, and $\mathrm{T}$ were very low in Xu et al. ' $\mathrm{S}^{\mathbf{1 0}}$ work. In both studies, a substantial amount of undesirable aromatics ( $m$-X, $m$-X, and $\mathrm{A} 9+)$ were reported.

In the literatures, the HZSM-5 used for methanol to aromatics contained high amount of Brønsted acid sites (BAS) compared to that of Lewis acid sites (LAS). ${ }^{\mathbf{3 , 9 , 1 0 , 1 3}} \mathrm{Zn}$ impregnation on such HZSM-5 decreased BAS and increased LAS significantly. ${ }^{3,9,10,13}$ This resulted in an increase in the aromatics selectivity and a decrease in alkanes selectivity., ${ }^{3,9,10,13}$ The increase in the aromatic selectivity was attributed to Zn-LAS $\left(\mathrm{ZnOH}^{+}\right)$that could accelerate aromatization and dehydrogenation reactions. The selectivity of alkenes varied in different studies, however. For example, Zhang et al. ${ }^{9}$ and Xu et al. ${ }^{10}$ reported an increase in alkenes selectivity while Li et al. ${ }^{13}$ reported a small decrease in alkenes selectivity.

Si deposition on HZSM-5 decreased BAS and LAS respectively. ${ }^{13,16}$ The deposition appeared to decrease the aromatics selectivity. ${ }^{\mathbf{1 3 , 1 6}}$ Most of the reduction was probably due to the absence of acid sites outside the zeolitic pores. The effects of $\mathrm{Si}$ deposition on alkenes and alkanes selectivities were very different in the literatures, however. Li et al. ${ }^{13}$ reported that although alkenes selectivity had increased to $8.9 \%$, alkanes was still the main product with its selectivity increased to $49.7 \%$. On the other hand, Li et al. ${ }^{16}$ showed that alkanes selectivity had dropped sharply and that alkenes had become the most abundant product.

Zn impregnation on Si/HZSM-5 significantly decreased BAS and increased LAS inside the zeolitic pores of Si/HZSM-5. ${ }^{13}$ This resulted in an increase in aromatics selectivity and a significant decrease in alkanes selectivity with a minor increase in alkenes selectivity. The increase in aromatics selectivity was attributed to the increased Zn-LAS inside the zeolitic pores of Si/HZSM-5 that promoted aromatization and dehydrogenation reactions.

From the aforementioned results, we can see that the product selectivities of methanol conversion could be manipulated with $\mathrm{Zn}$ impregnation and Si passivation. In this work, the technical feasibility of methanol to phenol was evaluated using HZSM-5, Zn/HZSM-5, Si/HZSM-5, and Zn/Si/HZSM-5 as catalysts. The effects of $\mathrm{Zn}$ impregnation, Si passivation, acidic sites, and process conditions on catalyst performance were analyzed.

\section{Experimental section}

\subsection{Catalyst preparation}

$\mathrm{NH}_{4}$-ZSM-5 with a $\mathrm{SiO}_{2} / \mathrm{Al}_{2} \mathrm{O}_{3}$ molar ratio of 30 with approximately 0.3 to $0.5 \mu \mathrm{m}$ crystal $\operatorname{size}^{17}$ (obtained from Zeolyst International) was pressed (10 tons $\mathrm{cm}^{-2}$ for $1 \mathrm{~min}$ ), crushed and sieved to get $\mathrm{NH}_{4}-\mathrm{ZSM}-5$ pellets of 30-50 mesh. Silica deposition on these $\mathrm{NH}_{4}$-ZSM-5 pellets was carried out using chemical liquid deposition of polyphenylmethylsiloxane (PPMS). Typically, $\mathrm{NH}_{4}$-ZSM-5 pellets $(60.0 \mathrm{~g})$ were added to a mixture of $n$-hexane (200.0 g) and PPMS (17.17 g, $4 \mathrm{wt} \% \mathrm{SiO}_{2}$ with respect to the zeolite) followed by rotating the solid-liquid mixture for 0.5 hour (h) at ambient temperature. After $0.5 \mathrm{~h}, n$ hexane was rota-evaporated under vacuum to obtain PPMSmodified $\mathrm{NH}_{4}$-ZSM-5 which was further calcined at $120{ }^{\circ} \mathrm{C}$ first in $\mathrm{N}_{2}\left(350 \mathrm{ml} \mathrm{min}{ }^{-1}, 1.5 \mathrm{~h}\right.$ ) and then in the air (350 $\mathrm{ml} \min ^{-1}, 6 \mathrm{~h}$ ) at $550{ }^{\circ} \mathrm{C}$ to obtain silica deposited HZSM-5. The procedure was repeated three times to obtain the final external surface passivated catalyst denoted as Si/HZSM-5.

The $\mathrm{NH}_{4}-\mathrm{ZSM}-5$ powder was calcined at $550{ }^{\circ} \mathrm{C}$ for $5 \mathrm{~h}$ under $\mathrm{N}_{2}$ atmosphere to obtained HZSM-5 powder. The HZSM-5 powder $(15 \mathrm{~g})$ was wet impregnated with a solution of zinc nitrate hexahydrate $(0.69 \mathrm{~g}$ in $12 \mathrm{ml}$ water $)$ and aged for $2 \mathrm{~h}$ to attend equilibrium. After $2 \mathrm{~h}$, the mixture was directly calcined under $\mathrm{N}_{2}$ atmosphere $\left(350 \mathrm{ml} \mathrm{min}^{-1}\right)$ for $3 \mathrm{~h}$ at $120{ }^{\circ} \mathrm{C}$ and then at $550{ }^{\circ} \mathrm{C}$ for $5 \mathrm{~h}$ to obtain theoretically $1 \mathrm{wt} \% \mathrm{Zn}$ impregnated HZSM-5, which was pressed (10 tons $\mathrm{cm}^{-2}$ for $1 \mathrm{~min}$ ), crushed, and sieved to obtain catalyst pellets of 30-50 mesh denoted as $1.0 \mathrm{wt} \% \mathrm{Zn} / \mathrm{HZSM}-5$. The Zn was impregnated on Si/HZSM-5 pellets using the similar procedure used for $1.0 \mathrm{wt} \% \mathrm{Zn} /$ HZSM-5. The Si/HZSM-5 (15 g) were wet impregnated with a solution of zinc nitrate hexahydrate $(0.69 \mathrm{~g}$ in $12 \mathrm{ml}$ water $)$ and aged for $2 \mathrm{~h}$ to attend equilibrium. After $2 \mathrm{~h}$, the mixture was directly calcined under $\mathrm{N}_{2}$ atmosphere $\left(350 \mathrm{ml} \mathrm{min}^{-1}\right)$ for $3 \mathrm{~h}$ at $120{ }^{\circ} \mathrm{C}$ and then at $550{ }^{\circ} \mathrm{C}$ for $5 \mathrm{~h}$ to obtain theoretically $1 \mathrm{wt} \%$ Zn impregnated Si/HZSM-5 denoted as $1.0 \mathrm{wt} \% \mathrm{Zn} / \mathrm{Si} / \mathrm{HZSM}-5$. Similarly, $1.5 \mathrm{wt} \% \mathrm{Zn}$ was impregnated on Si/HZSM-5 to obtain theoretically $1.5 \mathrm{wt} \% \mathrm{Zn}$ impregnated Si/HZSM-5 denoted as $1.5 \mathrm{wt} \% \mathrm{Zn} / \mathrm{Si} / \mathrm{HZSM}-5$.

\subsection{Catalysts characterization}

2.2.1 X-rays diffraction (XRD) measurements. X-ray diffraction data were obtained at a $\mathrm{Cu}-\mathrm{K} \alpha$ radiation $(\alpha=$ $1.5418 \mathrm{~A}^{0}$ ) operated at $40 \mathrm{kV}$ and $20 \mathrm{~mA}$. The samples were scanned between a $2 \theta$ range of $5^{\circ}-60^{\circ}$ at $5^{\circ} \mathrm{min}^{-1}$ (Ultima IV, Rigaku, 9407F701).

2.2.2 BET measurements. The specific surface area and pore volume of the catalysts were measured by $\mathrm{N}_{2}$ adsorptiondesorption at $77 \mathrm{~K}$ (Micromeritcs ASAP 2020). Before the measurement, the zeolite samples were degassed at $400{ }^{\circ} \mathrm{C}$ for $8 \mathrm{~h}$.

2.2.3 Temperature programmed desorption of $\mathrm{NH}_{3} \mathbf{N H}_{3}$ TPD). $\mathrm{NH}_{3}$-TPD was performed on a Micromeritics AutoChem II chemisorption analyzer equipped with a TCD detector. Approximately $100 \mathrm{mg}$ of sample was heated to $550{ }^{\circ} \mathrm{C}$ at the rate of $10{ }^{\circ} \mathrm{C} \mathrm{min}{ }^{-1}$ under He flow of $50 \mathrm{ml} \mathrm{min}{ }^{-1}$. The temperature was maintained at $550{ }^{\circ} \mathrm{C}$ for $1 \mathrm{~h}$ to remove adsorbed water and other gases. After cooling down to $150{ }^{\circ} \mathrm{C}$, the He flow was switched with a flow of 10 mole\% $\mathrm{NH}_{3}$ in He at $25 \mathrm{ml} \mathrm{min}^{-1}$ for $1.5 \mathrm{~h}$ to facilitate the adsorption of $\mathrm{NH}_{3}$ on the sample. After adsorption of $\mathrm{NH}_{3}$, the sample was purged with a He flow at 25 $\mathrm{ml} \mathrm{min}{ }^{-1}$ for $1 \mathrm{~h}$ at $150{ }^{\circ} \mathrm{C}$ to remove physisorbed $\mathrm{NH}_{3}$. Then the sample temperature was programmed to $650{ }^{\circ} \mathrm{C}$ at the rate of $10{ }^{\circ} \mathrm{C} \min ^{-1}$ and the signal was measured using a TCD.

2.2.4 Acidity measurement by pyridine and 2,4,6-trimethylpyridine FTIR. Pyridine adsorption infrared spectra (Py-IR) were measured on a PerkinElmer Spectrum One FT-IR Spectrometer equipped with TGS detector. First, the self-supporting sample pellet (approximately $70 \mathrm{mg}, 13 \mathrm{~mm}$ in diameter) was 
heated to $400{ }^{\circ} \mathrm{C}$ for $1 \mathrm{~h}$ under high vacuum in a Harrik hightemperature cell to remove moisture and other adsorbed gases from the sample. The spectrum of the self-supporting sample pellet was recorded at $150{ }^{\circ} \mathrm{C}$ and used as a background for the adsorbed pyridine test. After recording the background, the selfsupporting pellet was cooled to room temperature and soaked in the pyridine for $30 \mathrm{~min}$. After soaking, the self-supporting pellet was heated at $150{ }^{\circ} \mathrm{C}$ for $1 \mathrm{~h}$ in $\mathrm{N}_{2}$ flowrate $\left(15 \mathrm{ml} \mathrm{min}^{-1}\right)$ to remove physisorbed pyridine and then Py-IR spectra was recorded. Afterward, the catalyst sample was respectively heated to 250 , and $350{ }^{\circ} \mathrm{C}$. At each temperature, the catalyst sample was heated for $1 \mathrm{~h}$ respectively in $\mathrm{N}_{2}$ flowrate $\left(15 \mathrm{ml} \mathrm{min}^{-1}\right)$ and a PyIR spectrum was recorded at the respective temperature. The same procedure was used to determine total external acid sites using a probe molecule 2,4,6-trimethylpyridine (kinetic diameter $0.74 \mathrm{~nm}$ ). The concentration of acid sites on the catalysts was calculated by the following equation. ${ }^{18}$

$$
\begin{aligned}
& C_{\mathrm{L}}=\left(\pi / \mathrm{IMEC}_{\mathrm{L}}\right) \times\left(r^{2} / w\right) \times A_{1450} \\
& C_{\mathrm{B}}=\left(\pi / \mathrm{IMEC}_{\mathrm{B}}\right) \times\left(r^{2} / w\right) \times A_{1540}
\end{aligned}
$$

Where $C_{\mathrm{L}}$ and $C_{\mathrm{B}}$ are the concentration of Lewis (L) and Brønsted (B) acid sites in $\mu \mathrm{mol} \mathrm{g}{ }^{-1} ; A_{1450}$ and $A_{1540}$ are integrated areas of bands at 1450, and $1540 \mathrm{~cm}^{-1}$; $\mathrm{IMEC}_{\mathrm{L}}$, and IMEC $_{B}$ are molar extinction coefficients of 2.22 and $1.67 \mathrm{~cm}$ $\mu \mathrm{mol}^{-1}$, respectively. $r$ is the pellet radius in $\mathrm{cm}$ and $w$ is the pellet weight in $\mathrm{mg}$.

\subsection{Catalyst activity measurement}

The conversion of methanol was performed in a continuous fix bed stainless steel reactor (54 cm in length and $1.27 \mathrm{~cm}$ inner diameter) at $430{ }^{\circ} \mathrm{C}$ and $0.1 \mathrm{MPa}$. A schematic view of the lab scale setup is shown in Fig. 1. The desired amount of catalyst was loaded in the center of the reactor and the catalyst bed was heated in $\mathrm{N}_{2}$ stream from ambient temperature to $430{ }^{\circ} \mathrm{C}$. The temperature of the catalyst bed was monitored using three $\mathrm{K}$ type thermocouples (TC) placed on the external surface of the reactor wall as shown in Fig. 1. After reaching the desired temperature of $430{ }^{\circ} \mathrm{C}$, the $\mathrm{N}_{2}$ flow was shut-off and a methanol flow ( $\left.0.1 \mathrm{ml} \mathrm{min}^{-1}\right)$ was cut in using a calibrated syringe pump. The methanol passed through a preheater at $235{ }^{\circ} \mathrm{C}$, then into the reactor over the catalyst bed.

The gaseous product mixture at the reactor outlet was passed through the condenser maintained at $-5{ }^{\circ} \mathrm{C}$ to separate the gas and liquid products. The gaseous hydrocarbons were analyzed by a GC (Agilent 7890B) equipped with a capillary column (DB-1) on FID mode and non-hydrocarbons $\left(\mathrm{CO}, \mathrm{CO}_{2}\right.$, and $\left.\mathrm{H}_{2}\right)$ were analyzed using capillary column (ShinCarbon ST 120) on TCD mode. The volume of gas was measured by a wet test gas meter. The gas was sampled and analyzed online two times to obtain the two data points for gas composition. The first sample was taken at 5 minutes after cutting in methanol and the second sample at 60 minutes. For the test of $1.5 \mathrm{wt} \% \mathrm{Zn} / \mathrm{Si} / \mathrm{HZSM}-5$, however, only the 60 min sample was taken. Then the weight of gas component $i$ was obtained by combining the two gas readings from the experimental data of gas products.

The liquid products were sampled and analyzed offline at 60 min after cutting in methanol. The liquid hydrocarbons were separated from the water and analyzed on a GC (Agilent 7890B) equipped with a capillary column (DB-1) on FID mode. A second GC (Agilent 7820A) equipped with a capillary column (HPINNOWAX) on FID mode was used to determine the composition of xylene $(\mathrm{X})$ isomers. The water was also analyzed on a GC (Agilent 7890B) equipped with a capillary column (DB-1) in FID mode to analyze DME, methanol or hydrocarbon if present. Then the weight of component $i$ in liquid hydrocarbons was calculated from the experimental data of liquid hydrocarbon

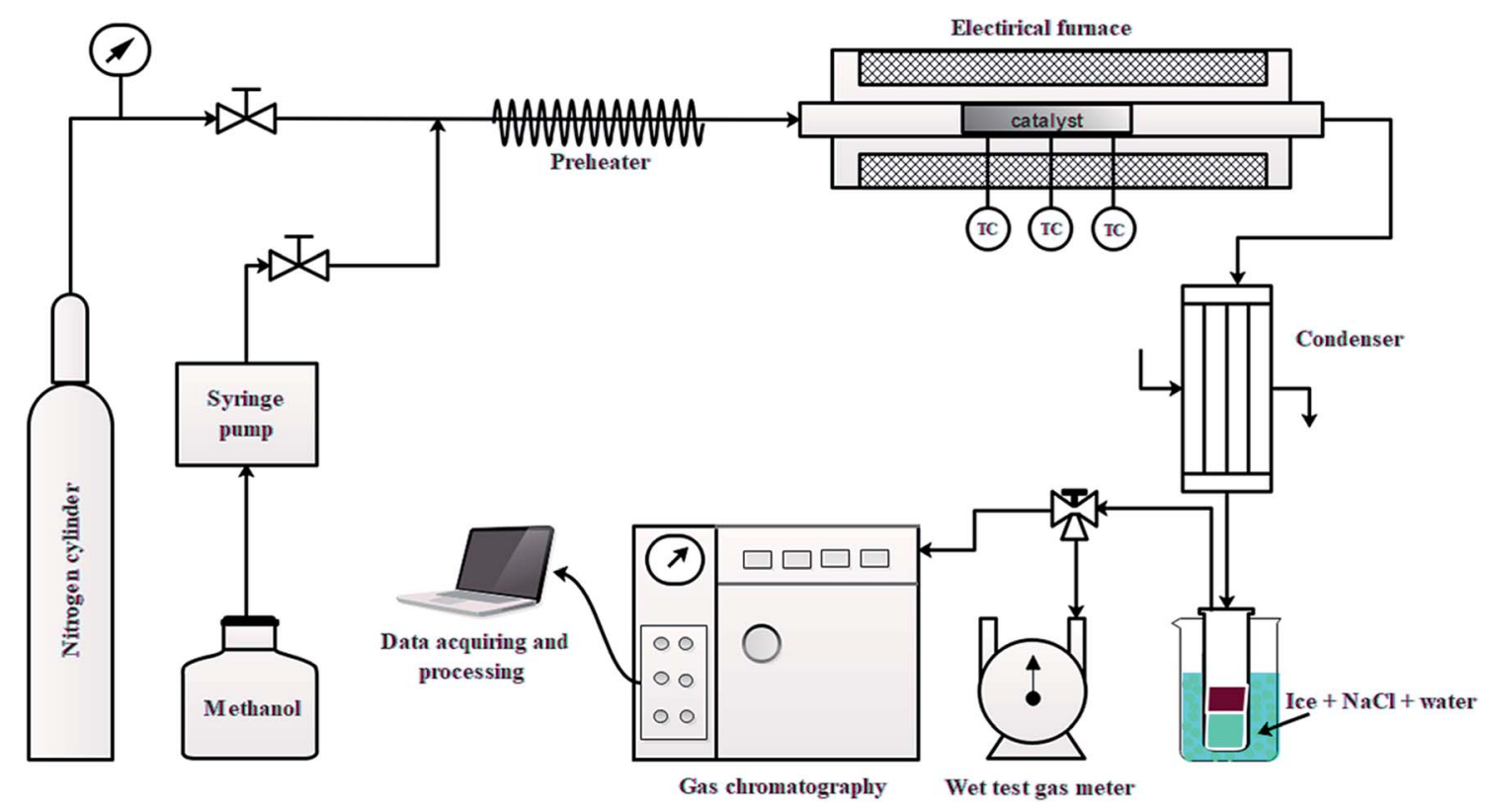

Fig. 1 A schematic view of the lab scale setup. 
products. The conversion of methanol, the selectivity of component $i$ and the carbon balance were calculated by the following equations.

Conversion of methanol $(\%)=\frac{\mathrm{MeOH}_{\text {in }}-\mathrm{MeOH}_{\text {out }}}{\mathrm{MeOH}_{\text {in }}} \times 100$

Selectivity of component $i(\mathrm{wt} \%)$

$$
=\frac{\text { Weight of component } i}{\text { Weight of hydrocarbons and nonhydrocarbons }} \times 100
$$

$$
\text { Carbon balance }(\%)=\frac{\mathrm{WC}_{\text {out }}}{\mathrm{WC}_{\mathrm{in}}} \times 100
$$

Where $\mathrm{WC}_{\text {out }}$ is the weight of the outlet $\mathrm{C}$ element and $\mathrm{WC}_{\mathrm{in}}$ is the weight of the inlet $\mathrm{C}$ element.

The $\mathrm{C}_{4}$-hydrogen transfer index $\left(\mathrm{C}_{4}-\mathrm{HTI}\right)$, which is a parameter to measure the activity for hydrogen transfer ${ }^{\mathbf{1 9 , 2 0}}$ was calculated as the combined selectivity of $n$-butane and iso-butane divided by the total $\mathrm{C}_{4}$ selectivity. The selectivity of hydrogen $\left(\mathrm{H}_{2}\right)$ from aromatization was separated from the selectivity of $\mathrm{H}_{2}$ from methanol decomposition using the following equation.

Selectivity of $\mathrm{H}_{2}\left(\mathrm{wt}^{\mathrm{o}} \%\right)$

$$
=\frac{\text { Weight of } \mathrm{H}_{2}-\text { Weight of } \mathrm{H}_{2} \text { from } \mathrm{CO}_{x}}{\text { Weight of hydrocarbons and nonhydrocarbons }}
$$

In the conversion of methanol, the molecular $\mathrm{H}_{2}$ generated is attributed to the two aspects. First due to aromatization reaction and second due to methanol decomposition which forms $\mathrm{CO}_{x}$ and $\mathrm{H}_{2}$. Hence, the selectivity of $\mathrm{H}_{2}$ calculated using the above equation can be used to verify aromatization reactions on the catalysts.

The weight of $\mathrm{H}_{2}$ from methanol decomposition can be estimated from the amounts of $\mathrm{CO}$ and $\mathrm{CO}_{2}$ found in the reaction products based on the following reaction equations.

$$
\begin{gathered}
\mathrm{CH}_{3} \mathrm{OH}+\mathrm{H}_{2} \mathrm{O} \rightarrow \mathrm{CO}_{2}+3 \mathrm{H}_{2} \\
\mathrm{CH}_{3} \mathrm{OH} \rightarrow \mathrm{CO}+2 \mathrm{H}_{2}
\end{gathered}
$$

\section{Results and discussion}

\subsection{Physical and chemical properties of catalysts}

3.1.1 X-rays diffraction (XRD) analysis. The Fig. 2 shows the XRD patterns of the catalysts. From Fig. 2, it can be seen that the XRD peaks for the modified HZSM-5 catalysts were very similar to those of HZSM-5. No new diffraction peak was observed which suggested that the MFI structure of HZSM-5 catalyst was intact and no new phase was produced after the modification of HZSM-5 catalyst. ${ }^{13}$ No characteristic diffraction peak of $\mathrm{SiO}_{2}(2 \theta$ $=22^{\circ}$ ) on Si modified HZSM-5 was observed suggesting silica species were well dispersed on the external surface outside the pores of the HZSM-5. No characteristic diffraction peaks of $\mathrm{ZnO}$

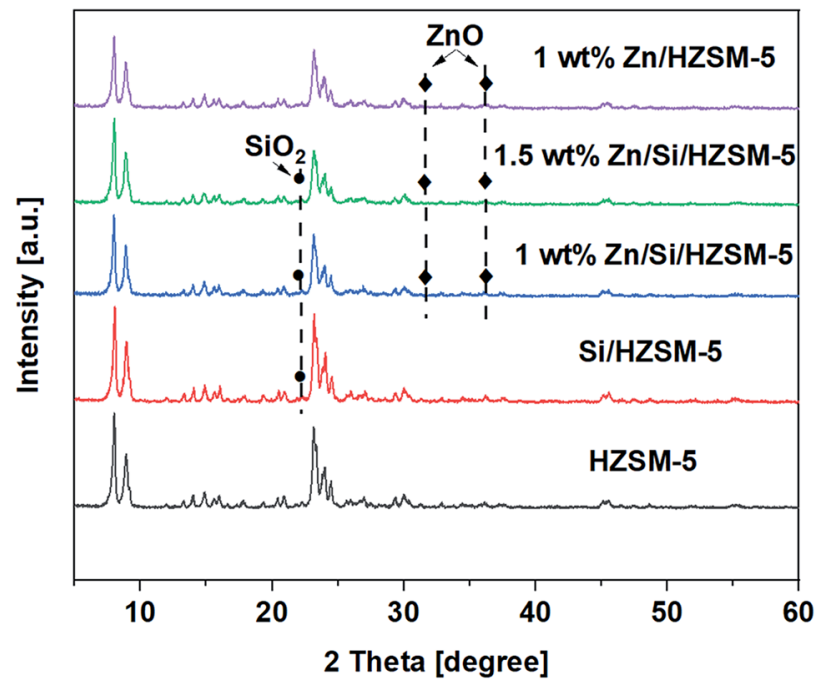

Fig. 2 XRD patterns of the parent HZSM-5, and the modified HZSM-5 catalysts.

$\left(2 \theta=31.6^{\circ}, 36.1^{\circ}\right)$ were observed on $\mathrm{Zn}$ modified catalysts, suggesting that Zn species were highly dispersed ${ }^{\mathbf{8 1 2}}$ on HZSM-5 and $\mathrm{Zn} / \mathrm{Si} / \mathrm{HZSM}-5$ catalysts.

3.1.2 Surface areas and pore volumes. The results of $\mathrm{N}_{2}$ adsorption of the catalysts are listed in Table 1 , from Table 1 it can be seen that the specific surface area and the pore volume decreased on Si/HZSM-5 catalyst. The silica deposition occurred preferentially on the external surface of the HZSM-5 catalyst because PPMS is too large in molecular size to enter the zeolite channels. ${ }^{13}$

The decrease in the pore volume on the Si/HZSM-5 catalyst was probably due to channel blocking by the silica deposition. The $\mathrm{Zn}$ impregnation on HZSM-5 did not seem to affect the specific surface area and the pore volume to a greater extent compared to that of HZSM-5 catalyst. The impregnation of Zn on Si/HZSM-5 catalyst further decreased moderately the specific surface area and the pore volume compared to that of the Si/HZSM- 5 catalyst.

3.1.3 Acidity of catalysts. The amount and strength of acid sites on HZSM-5 and modified catalysts were determined by

\begin{tabular}{|c|c|c|c|c|c|}
\hline \multirow[b]{2}{*}{ Catalysts } & \multicolumn{2}{|c|}{$\begin{array}{l}\text { Specific surface } \\
\text { area }\left(\mathrm{m}^{2} \mathrm{~g}^{-1}\right)\end{array}$} & \multicolumn{3}{|c|}{ Pore volume $\left(\mathrm{cm}^{3} \mathrm{~g}^{-1}\right)$} \\
\hline & ${ }^{a} S_{\mathrm{BET}}$ & ${ }^{b} S_{\text {micropore }}$ & $P_{\mathrm{vol}}$ & ${ }^{b} V_{\text {micro }}$ & ${ }^{c} V_{\text {mesopore }}$ \\
\hline HZSM-5 & 322 & 216 & 0.26 & 0.12 & 0.15 \\
\hline $1 \mathrm{wt} \% \mathrm{Zn} / \mathrm{HZSM}-5$ & 321 & 199 & 0.25 & 0.11 & 0.15 \\
\hline Si/HZSM-5 & 258 & 196 & 0.23 & 0.11 & 0.12 \\
\hline 1 wt\% Zn/Si/HZSM-5 & 244 & 185 & 0.21 & 0.10 & 0.11 \\
\hline $1.5 \mathrm{wt} \% \mathrm{Zn} / \mathrm{Si} / \mathrm{HZSM}-5$ & 235 & 178 & 0.20 & 0.09 & 0.10 \\
\hline
\end{tabular}
$\mathrm{NH}_{3}$-TPD. The $\mathrm{NH}_{3}$-TPD profiles of the catalysts are shown in Fig. 3. The amount of acid sites obtained on different catalysts is given in Table 2.

Table 1 Textures of HZSM-5 and modified HZSM-5 catalysts 


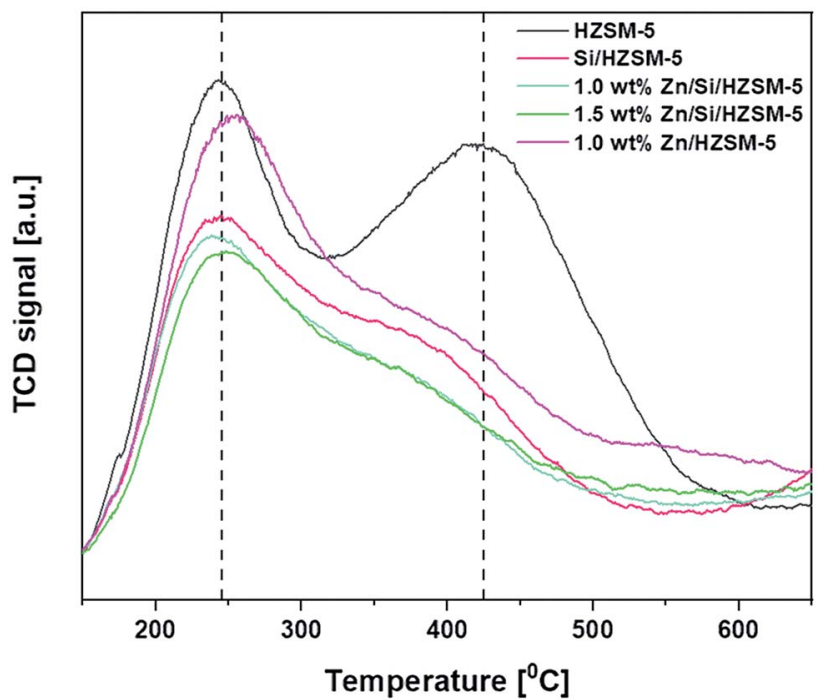

Fig. $3 \mathrm{NH}_{3}$-TPD profiles of HZSM-5, Zn/HZSM-5, Si/HZSM-5, and Zn/ $\mathrm{Si} / \mathrm{HZSM}-5$.

Table 2 Acidity information of catalysts by $\mathrm{NH}_{3}-\mathrm{TPD}$

Amount of acid sites $\left(\mu \mathrm{mol} \mathrm{g}^{-1}\right)$

\begin{tabular}{llll} 
Catalyst & Total & Medium $\left(150-350{ }^{\circ} \mathrm{C}\right)$ & Strong $\left(>350{ }^{\circ} \mathrm{C}\right)$ \\
\hline HZSM-5 & 660 & 230 & 430 \\
1.0 wt $\%$ Zn/HZSM-5 & 477 & 252 & 225 \\
Si/HZSM-5 & 367 & 200 & 167 \\
1.0 wt\% Zn/Si/HZSM-5 & 330 & 180 & 150 \\
1.5 wt $\%$ Zn/Si/HZSM-5 & 306 & 173 & 133
\end{tabular}

From Fig. 3, two typical desorption peaks for the HZSM-5 catalyst centering at around $245{ }^{\circ} \mathrm{C}$ and $425{ }^{\circ} \mathrm{C}$ are observed and are ascribed to $\mathrm{NH}_{3}$ desorption from medium and strong acid sites, respectively.
The high-temperature peak observed around $425{ }^{\circ} \mathrm{C}$ reduced to a greater extent for all $\mathrm{Zn}$-impregnated catalysts. From Fig. 3, it can be said that the impregnation of $\mathrm{Zn}$ on HZSM-5 not only shifted the peak position from $245{ }^{\circ} \mathrm{C}$ to $255{ }^{\circ} \mathrm{C}$ but also reduced the total acidity. In particular, the amount of strong acid sites reduced from $430 \mu \mathrm{mol} \mathrm{g}{ }^{-1}$ to 225 $\mu \mathrm{mol} \mathrm{g}^{-1}$. However, the amount of medium acid sites increased slightly from $230 \mu \mathrm{mol} \mathrm{g}^{-1}$ to $252 \mu \mathrm{mol} \mathrm{g}^{-1}$ (Table 2). Silica deposition on HZSM-5 not only changed the peak position of acid sites from $425{ }^{\circ} \mathrm{C}$ on HZSM-5 to $380{ }^{\circ} \mathrm{C}$ but also decreased amount of medium acid sites from 230 to $200 \mu \mathrm{mol}$ $\mathrm{g}^{-1}$ and amount of strong acid sites from 430 to $167 \mu \mathrm{mol} \mathrm{g}^{-1}$. The impregnation of $\mathrm{Zn}$ on Si/HZSM-5 further decreased amount of both medium and strong acid site compared to that of HZSM-5. The amount of medium acid sites were $180 \mu \mathrm{mol}$ $\mathrm{g}^{-1}$ and $173 \mu \mathrm{mol} \mathrm{g}^{-1}$ on $1.0 \mathrm{wt} \% \mathrm{Zn} / \mathrm{Si} / \mathrm{HZSM}-5$ and $1.5 \mathrm{wt} \%$ $\mathrm{Zn} / \mathrm{Si} / \mathrm{HZSM}-5$, respectively. The amount of strong acid sites were $150 \mu \mathrm{mol} \mathrm{g}^{-1}$ and $133 \mu \mathrm{mol} \mathrm{g}{ }^{-1}$ on $1.0 \mathrm{wt} \% \mathrm{Zn} / \mathrm{Si} / \mathrm{HZSM}-5$ and $1.5 \mathrm{wt} \% \mathrm{Zn} / \mathrm{Si} / \mathrm{HZSM}-5$, respectively.

The Py-IR was performed to detect the nature and amount of acid sites. Fig. 4a shows the pyridine spectra of unmodified and modified HZSM- 5 catalysts. The amount of total acid sites, LAS and BAS of the catalysts are given in Table 3 .

Fig. 4a shows that three characteristic peaks around 1453, 1540 , and $1490 \mathrm{~cm}^{-1}$, which can be attributed to LAS, BAS, and LAS + BAS sites, ${ }^{21}$ appeared in all of the samples. From Fig. 4a, for HZSM-5 catalyst, it can be observed that the number of the BAS are much more compared to that of the LAS indicating that BAS dominate on the HZSM-5 catalyst. The impregnation of Zn on HZSM-5 sharply increased LAS and decreased BAS. The amount of total acid sites on $1.0 \mathrm{wt} \% \mathrm{Zn} / \mathrm{HZSM}-5$ decreased from $300 \mu \mathrm{mol} \mathrm{g}{ }^{-1}$ on HZSM-5 to $231 \mu \mathrm{mol} \mathrm{g}{ }^{-1}$. Hence, the nature of acid sites changes with the impregnation of $\mathrm{Zn}$ species. This phenomenon has been reported in may research papers. ${ }^{21-24}$ On Si/HZSM-5 catalyst, the amount of both BAS and LAS decreased, the amount of BAS decreased to a greater extent
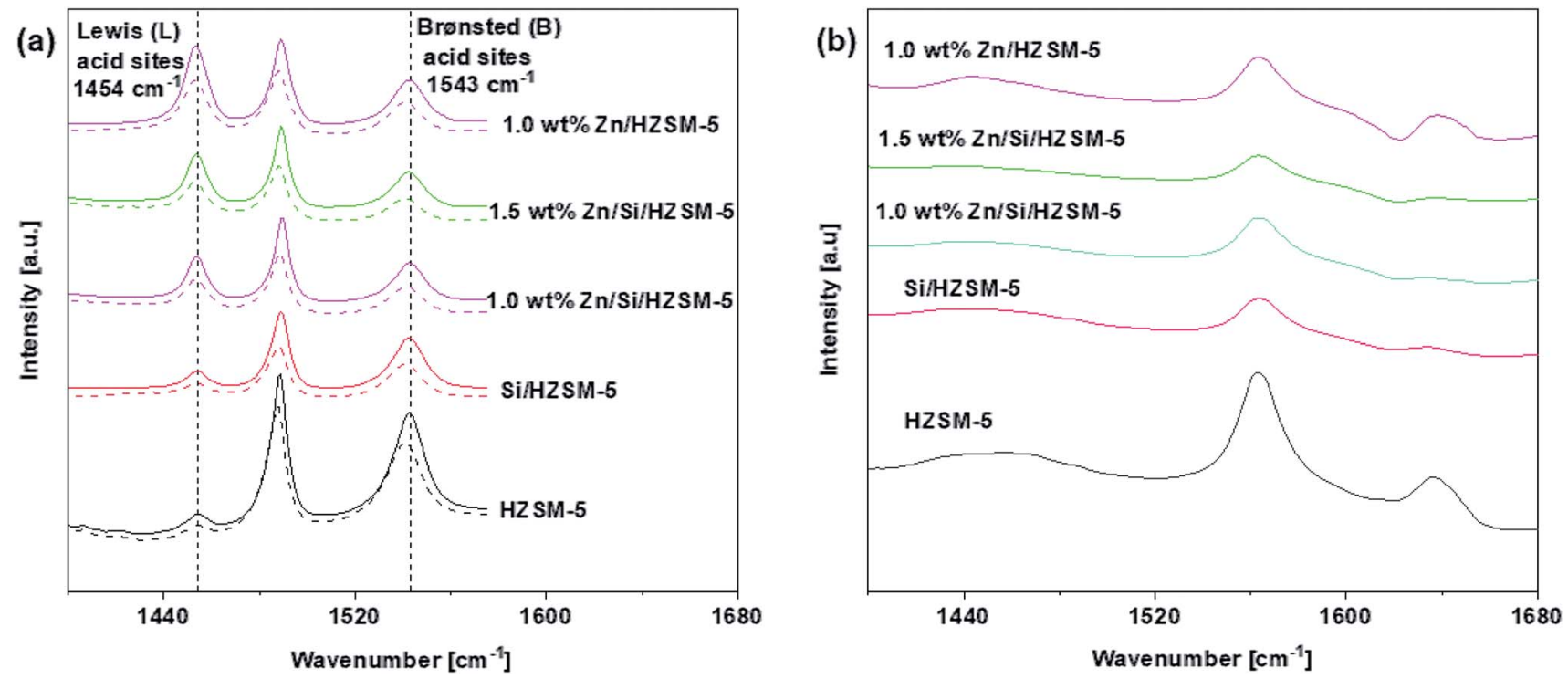

Fig. 4 (a) Py-FTIR of HZSM-5, Zn/HZSM-5, Si/HZSM-5, and Zn/Si/HZSM-5 (solid line for desorption at $250{ }^{\circ} \mathrm{C}$ and dashed line for desorption at $350{ }^{\circ} \mathrm{C}$ ). (b) 2,4,6-trimethylpyridine -FTIR of HZSM-5, Si/HZSM-5, and Zn/Si/HZSM-5 at $250{ }^{\circ} \mathrm{C}$. 
Table 3 The acidity of the catalysts measured from pyridine and 2,4,6trimethylpyridine IR

\begin{tabular}{|c|c|c|c|c|}
\hline \multirow[b]{2}{*}{ Catalyst } & \multicolumn{3}{|c|}{$\begin{array}{l}\text { Amount of acid sites } \\
\left(\mu \mathrm{mol} \mathrm{g}{ }^{-1}\right)\end{array}$} & \multirow{2}{*}{$\begin{array}{l}{ }^{b} \text { External } \\
\text { acidity/ } \\
\text { total } \\
\text { acidity (\%) }\end{array}$} \\
\hline & $\begin{array}{l}{ }^{a} \text { Total } \\
(\text { LAS + BAS })\end{array}$ & ${ }^{a}$ LAS & ${ }^{a} \mathrm{BAS}$ & \\
\hline HZSM-5 & 300 & 20 & 280 & 28 \\
\hline 1.0 wt $\%$ Zn/HZSM-5 & 231 & 108 & 123 & 25 \\
\hline Si/HZSM-5 & 160 & 16 & 144 & 6 \\
\hline $1.0 \mathrm{wt} \% \mathrm{Zn} / \mathrm{Si} / \mathrm{HZSM}-5$ & 158 & 52 & 106 & 3 \\
\hline $1.5 \mathrm{wt} \% \mathrm{Zn} / \mathrm{Si} / \mathrm{HZSM}-5$ & 147 & 59 & 88 & 5 \\
\hline
\end{tabular}

${ }^{a}$ determined by Py-IR. ${ }^{b}$ determined by 2,4,6-trimethylpyridine IR.

(Fig. 4a). The amount of total acid sites decreased significantly from $300 \mu \mathrm{mol} \mathrm{g}^{-1}$ on HZSM-5 to $160 \mu \mathrm{mol} \mathrm{g}{ }^{-1}$ on Si/HZSM-5.

The impregnation of $\mathrm{Zn}$ on Si/HZSM-5 catalysts increased the amount of LAS and decreased the amount of BAS (Fig. 4a). The amount of total acid sites on $1.0 \mathrm{wt} \% \mathrm{Zn} / \mathrm{Si} / \mathrm{HZSM}-5$ and $1.5 \mathrm{wt} \% \mathrm{Zn} / \mathrm{Si} / \mathrm{HZSM}-5$ were $158 \mu \mathrm{mol} \mathrm{g}{ }^{-1}$ and $147 \mu \mathrm{mol} \mathrm{g}{ }^{-1}$, respectively compared to that of $300 \mu \mathrm{mol} \mathrm{g}{ }^{-1}$ on HZSM-5. The change BAS and LAS is attributed to the strong interaction

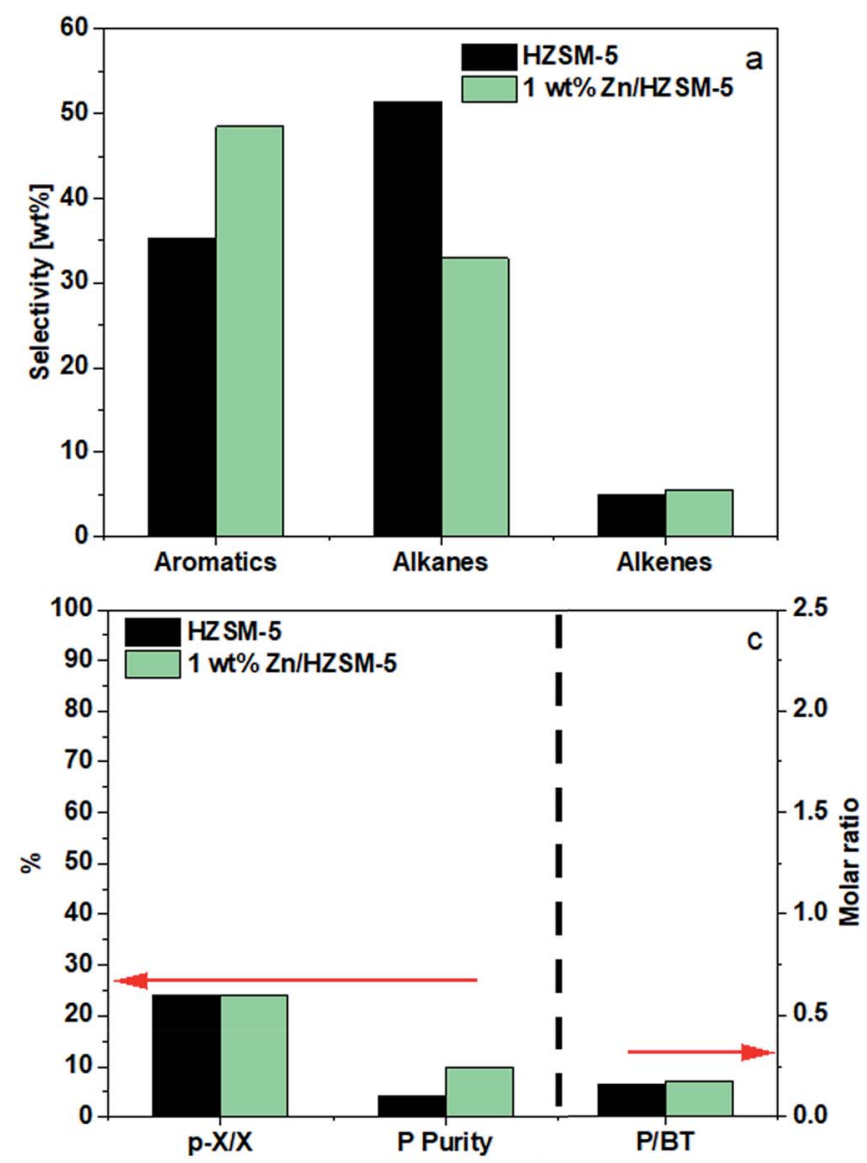

between the intrinsic acid sites and the $\mathrm{Zn}$ species due to which partial BAS are converted into $\mathrm{Zn}-\mathrm{LAS}^{\mathbf{2 1}}$ (preferentially $\mathrm{ZnOH}^{+}$ species). As reported in the literature, $\mathrm{Zn}$-LAS $\left(\mathrm{ZnOH}^{+}\right.$species) have the ability to accelerate the process of aromatization. ${ }^{25}$

The external acid sites determined using 2,4,6-trimethylpyridine is illustrated in Fig. $4 \mathrm{~b}$. The external acid sites account for $28 \%, 25 \%, 6 \%, 3 \%$ and $5 \%$ of the total acidity for HZSM-5, 1.0 wt\% Zn/HZSM-5, Si/HZSM-5, 1.0 wt\% Zn/Si/HZSM5, and $1.5 \mathrm{wt} \% \mathrm{Zn} / \mathrm{Si} / \mathrm{HZSM}-5$, respectively as shown in Table 3. The significant reduction in the acidity on $\mathrm{Si} / \mathrm{HZSM}-5$ and $\mathrm{Zn} / \mathrm{Si}$ / ZSM-5 validated that the external acid sites were significantly reduced after the catalyst modifications.

\subsection{Performance of the catalyst}

The conversion of methanol on all the catalysts was above 99.0\% for $1 \mathrm{~h}$ and no DME was detected under the reaction conditions used. The higher temperature favors decomposition of methanol to $\mathrm{CO}_{x}$ and $\mathrm{H}_{2}$ which can reduce the aromatic selectivity. Hence, all the experiments were performed at $430{ }^{\circ} \mathrm{C}$ to avoid high methanol decomposition. The carbon balance for all the runs was above $98 \%$.

3.2.1. Effect of zinc impregnation. The performance of $1.0 \mathrm{wt} \% \mathrm{Zn} / \mathrm{HZSM}-5$ in terms of product selectivity is shown in Fig. 5, also shown is that of HZSM-5 for comparison. The $\mathrm{C}_{4}$-HTI

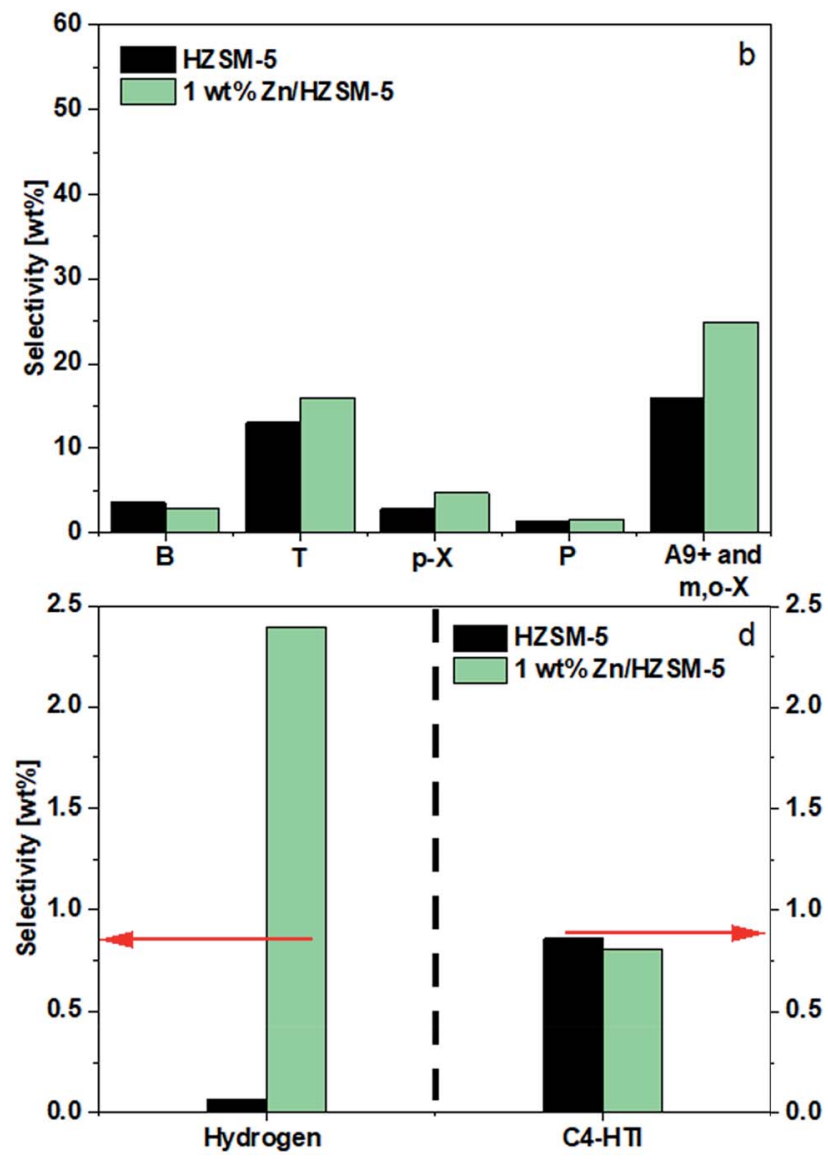

Fig. 5 (a) Selectivity of aromatics, alkanes, and alkenes on different catalysts. (b) Selectivity of $B, T, p-X, P, A 9+$ and $m, O-X$ on different catalysts. (c) $p-X / X, P$ purity and P/BT molar ratio. (d) Hydrogen selectivity and $C_{4}-\mathrm{HTI}$; Reaction conditions: $0.1 \mathrm{MPa}, 430{ }^{\circ} \mathrm{C}, \mathrm{WHSV}=1.6 \mathrm{~h}^{-1}$, the data were obtained at $1 \mathrm{~h}$. 
of the two catalysts is given in Fig. 5d. The HZSM-5 catalyst produced alkanes (51.4 wt $\%$ ) and aromatics (35.3 wt $\%$ ) as the main products. Amongst the aromatics, the desired BT $p$-X accounted for $19.4 \mathrm{wt} \%$, and the rest (16.0 wt\%) went to lowervalued $m-\mathrm{X}, o-\mathrm{X}$, and $\mathrm{A} 9+$. The $\mathrm{P} / \mathrm{BT}$ molar ratio was only at 0.2 . Compared to the performance of HZSM-5, $1.0 \mathrm{wt} \% \mathrm{Zn} / \mathrm{HZSM}-5$ shifted alkanes (18.4 wt\%) to aromatics (48.4 wt\%).

A good fraction of the shifting, however, was directed toward $m$-X, $o$-X, and A9+ (24.9 $\mathrm{wt} \%)$, resulting in a combined BT $p$-X selectivity of $23.6 \mathrm{wt} \%$. A small increase in the selectivity of alkenes (4.9 wt\% to 6.1 wt\%) was observed (Fig. 5a). The impregnation of $1.0 \mathrm{wt} \% \mathrm{Zn}$ had no appreciable effect on the $\mathrm{P}$ selectivity. However, the purity of $\mathrm{P}\left(\mathrm{P} / \mathrm{C}_{3}\right)$ increased due to a decrease in the selectivity of and $\mathrm{C}_{3}$ alkane (Fig. $5 \mathrm{c}$ ). The results on aromatics selectivity is consistent with those reported in the literature. The small increase in P selectivity (from $1.3 \mathrm{wt} \%$ to $1.6 \mathrm{wt} \%$ ) was similar to that of Zhang ${ }^{9}$ and Xu et al. ${ }^{10}$ It should be noted that the selectivity of $\mathrm{H}_{2}$ on HZSM-5 was less because the $\mathrm{H}_{2}$ generated from aromatization was most probably consumed via hydrogen transfer reaction to form alkanes. On $1.0 \mathrm{wt} \% \mathrm{Zn} /$ HZSM-5, hydrogen selectivity increased sharply and hydrogen transfer index decreased (Fig. 5d), indicating that zinc impregnation promoted aromatization, reduced hydrogen transfer, and facilitated the formation of hydrogen molecules.

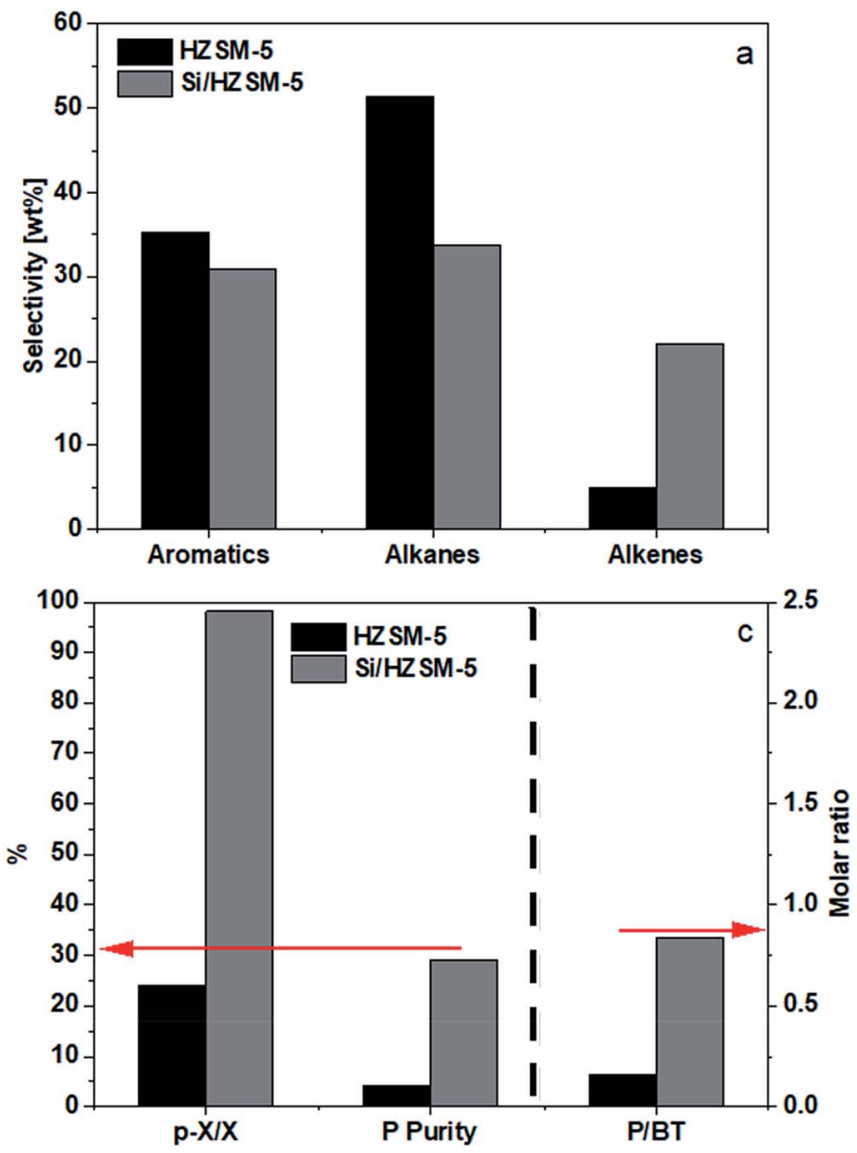

As shown in Fig. 5c, the HZSM-5 catalyst demonstrated a $\mathrm{P} /$ BT molar ratio of 0.2 . Impregnating $1.0 \mathrm{wt} \% \mathrm{Zn}$ had no effect on the $\mathrm{P} / \mathrm{BT}$ molar ratio.

3.2.2. Effect of external surface passivation. Silica deposition on HZSM-5 was accomplished using PPMS to selectively eliminate the acid sites outside the channels and increase the shape selectivity of HZSM-5. The changes in product distribution over Si/HZSM-5 catalyst compared to that of HZSM-5 are shown in Fig. 6. The Si/HZSM-5 catalyst showed an aromatics selectivity of $31.0 \mathrm{wt} \%$, of which the majority (29.4 wt\%) was the desired B, $\mathrm{T}$, and $p$-X, an alkenes selectivity of $22.0 \mathrm{wt} \%$, and an alkanes selectivity of $33.8 \mathrm{wt} \%$. Compared to the performance of HZSM-5, $\mathrm{Si} / \mathrm{HZSM}-5$ raised the combined BTp-X selectivity from $19.4 \mathrm{wt} \%$ to $29.4 \mathrm{wt} \%$, increased the P selectivity (from $1.3 \mathrm{wt} \%$ to $7.0 \mathrm{wt} \%$ ) and the alkenes selectivity (from $4.9 \mathrm{wt} \%$ to $22.0 \mathrm{wt} \%$ ), and reduced the alkanes selectivity (from $51.4 \mathrm{wt} \%$ to $33.8 \mathrm{wt} \%$ ).

The benefits of silica deposition are clear. It significantly reduced the combined selectivities of $\mathrm{A} 9+, m-\mathrm{X}$, and $o$-X from 16.0 to $1.6 \mathrm{wt} \%$, shifting these undesired aromatics to the wanted B, T, and p-X. Furthermore, the catalyst's shape selectivity raised the $p$-X selectivity from a mere $2.8 \mathrm{wt} \%$ to $11.5 \mathrm{wt} \%$, with the $p$-X purity in $\mathrm{X}$ reaching $98.2 \%$. Equally beneficial is the shifting of alkanes (decreasing from 51.4 to $33.8 \mathrm{wt} \%$ ) to $\mathrm{P}$ and alkenes. Fig. 6d showed a decreased $\mathrm{C}_{4}$-HTI, which was

Fig. 6 (a) Selectivity of aromatics, alkanes, and alkenes on different catalysts. (b) Selectivity of B, T, $p-X, P, A 9+$ and $m, o-X$ on different catalysts. (c) $p-X / X, P$ purity and P/BT molar ratio. (d) Hydrogen selectivity and $\mathrm{C}_{4}-\mathrm{HTl}$; Reaction conditions: $0.1 \mathrm{MPa}, 430{ }^{\circ} \mathrm{C}, \mathrm{WHSV}=1.6 \mathrm{~h}^{-1}$, the data were obtained at $1 \mathrm{~h}$. 
probably due to the loss of the acid sites on the external surface. As the change in aromatics selectivity was relatively minor compared to the decrease in alkanes selectivity and increase in alkenes selectivity, it may be inferred that a substantial amount of alkenes were converted into alkanes via the hydrogen transfer route on the surface outside the channels. Fig. 6c shows that silica deposition help raise the P/BT molar ratio from 0.2 to 0.8 .

3.2.3 Effect of zinc impregnation on Si/HZSM-5. The product distributions for the $\mathrm{Zn} / \mathrm{Si} / \mathrm{HZSM}-5$ catalysts are shown in Fig. 7. Unlike the shifting of alkanes to aromatics by impregnating Zn on HZSM-5, impregnating Zn on Si/HZSM-5 shifted alkanes to alkenes and P (Fig. 7a and b). Both $1.0 \mathrm{wt} \% \mathrm{Zn} / \mathrm{Si} / \mathrm{HZSM}-5$ and $1.5 \mathrm{wt} \% \mathrm{Zn} / \mathrm{Si} / \mathrm{HZSM}-5$ showed a significant shifting of alkanes to alkenes and $\mathrm{P}$, without changing much of the combined BTp-X selectivity. Li et al. $^{13}$ impregnated $1 \mathrm{wt} \%$ zinc on Si/HZSM-5 and observed a large increase in aromatics selectivity accompanied by a similarly large decrease in alkanes selectivity as well as decreases in alkenes and $\mathrm{P}$ selectivities. The differences observed between this work and Li et al. ${ }^{13}$ work may be due to variations in catalyst preparation methods, high amount of acidity on the catalyst, and reaction conditions. For instance, On Li et al. ${ }^{13} 1 \mathrm{wt} \% \mathrm{Zn} \mathrm{Si} / \mathrm{HZSM}-$ 5 , the total acidity determined by $\mathrm{NH}_{3}$-TPD was $1080 \mu \mathrm{mol} \mathrm{g}{ }^{-1}$ while in this work, the total acidity on $1 \mathrm{wt} \%$ and $1.5 \mathrm{wt} \% \mathrm{Zn}$ modified Si/HZSM-5 was 330 and $306 \mu \mathrm{mol} \mathrm{g}^{-1}$ respectively.

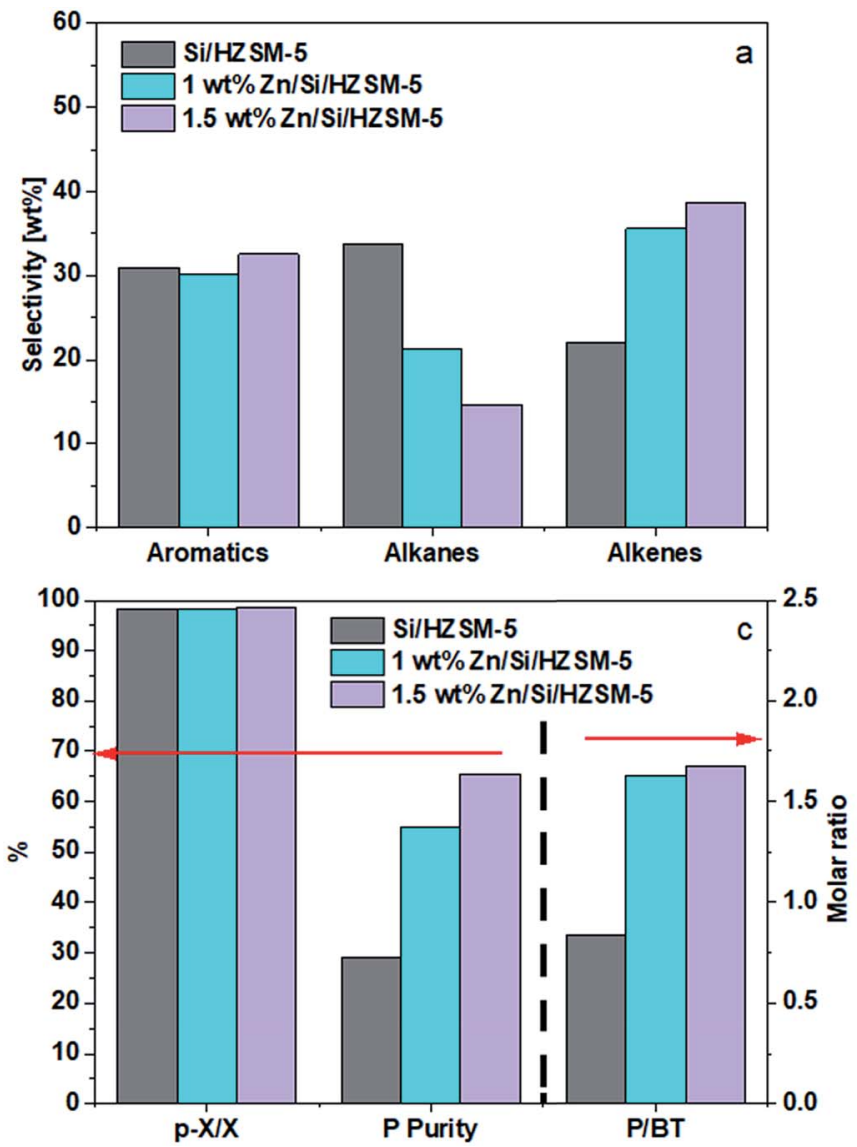

Thedifferences in performance between $1.0 \mathrm{wt} \% \mathrm{Zn}$ and $1.5 \mathrm{wt} \% \mathrm{Zn}$ were small, with $1.5 \mathrm{wt} \% \mathrm{Zn}$ making more alkenes and P. Compared to the performance of Si/HZSM-5, $1.5 \mathrm{wt} \% \mathrm{Zn} /$ Si/HZSM-5 further reduced alkanes selectivity (14.7 wt \%), raised alkenes selectivity (38.7 wt\%) and P selectivity (12.1 wt\%), and kept the combined BT $p$-X selectivity at $30.5 \mathrm{wt} \%$. The slightly lower selectivity of $\mathrm{H}_{2}$ (Fig. 7d) on $1.5 \mathrm{wt} \% \mathrm{Zn} / \mathrm{Si} / \mathrm{HZSM}-5$ compared to that of $1 \mathrm{wt} \% \mathrm{Zn} / \mathrm{Si} / \mathrm{HZSM}-5$ was most likely due to an experimental and/or instrumental error. Fig. 7d shows that $\mathrm{Zn}$ impregnation on Si/HZSM-5 promoted the formation of molecular hydrogen and suppressed the hydrogen transfer reaction, leading to an increase of propylene purity from 29.0 to $65.4 \%$ (Fig. 7c). Such a performance led to a P/BT molar ratio of 1.7 as shown in Fig. 7c. The catalyst $1.5 \mathrm{wt} \% \mathrm{Zn} / \mathrm{Si} / \mathrm{HZSM}-5$ was considered as better compared to that of other catalysts not only because it led to a high P/BT molar ratio of 1.7 but also showed higher selectivities towards $p$-X and alkenes simultaneously under reaction conditions used.

\subsection{Effect of acidity on the performance}

In this study, we were changing the nature of acidic sites, such as creating LAS and reducing BAS. Our analysis, therefore, focused on pyridine-adsorption data because pyridine

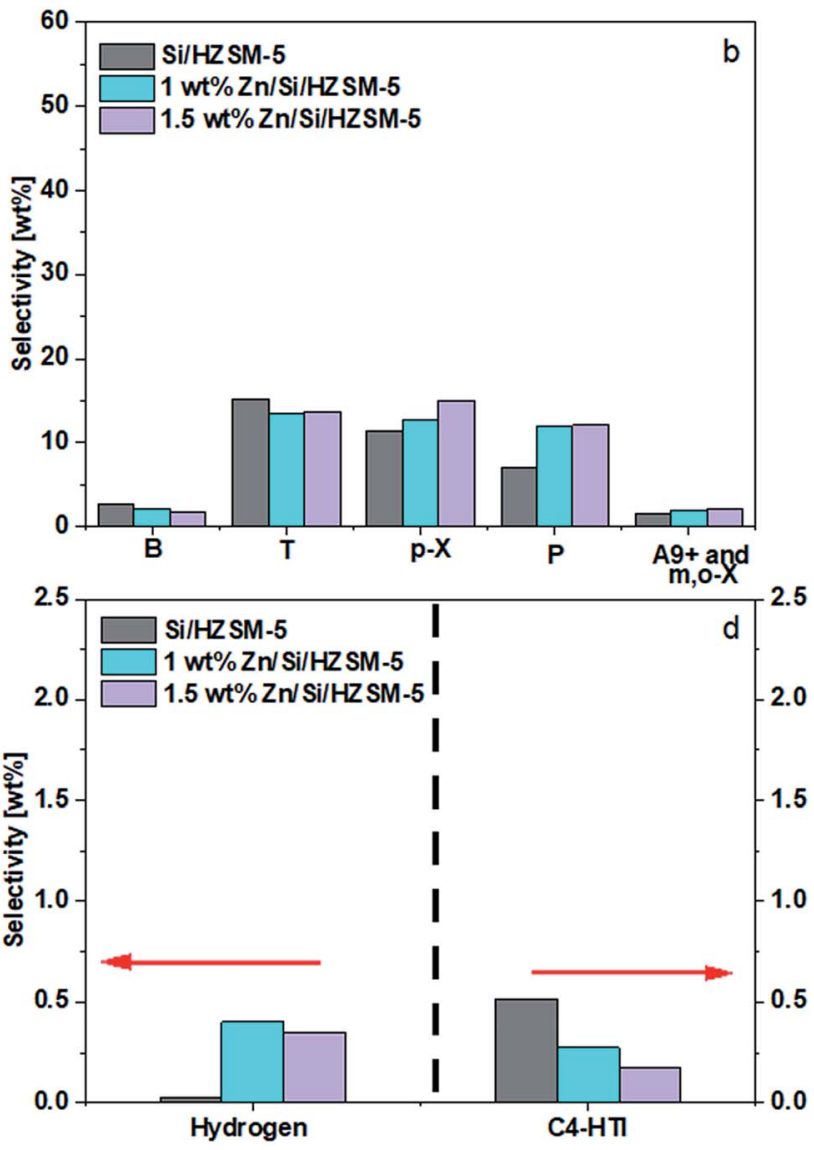

Fig. 7 (a) Selectivity of aromatics, alkanes, and alkenes on different catalysts. (b) Selectivity of $B, T, p-X, P, A 9+$ and $m, O-X$ on different catalysts. (c) $p-X / X, P$ purity and P/BT molar ratio. (d) Hydrogen selectivity and $\mathrm{C}_{4}-\mathrm{HTl}$; Reaction conditions: $0.1 \mathrm{MPa}, 430{ }^{\circ} \mathrm{C}, \mathrm{WHSV}=1.6 \mathrm{~h}^{-1}$, the data were obtained at $1 \mathrm{~h}$. 
adsorption provided more information on the nature of acidic sites than did $\mathrm{NH}_{3}$-TPD.

3.3.1. HZSM-5 vs. Zn/HZSM-5. Our HZSM-5 possessed a large quantity of BAS and a few LAS (Table 4). Considering the facts that HZSM-5 produced mainly alkanes and aromatics, and that the alkanes selectivity was much higher than the aromatics selectivity, one could infer that BAS promoted hydrogen transfer more strongly than aromatization as the very high alkanes selectivity and the relatively high C4-HTI indicated. Impregnation of $\mathrm{Zn}$ on the HZSM-5 reversed the alkanes and the aromatics selectivities. Zn/HZSM-5 still produced mainly alkanes and aromatics, but now the aromatics selectivity was much higher than the alkanes selectivity. Pyridine data showed that $\mathrm{Zn}$ impregnation reduced BAS, but increased LAS, both substantially. The decrease of BAS was more than the increase of LAS, however, leading to a net decrease of total acidic sites. It seemed apparent that the Zn-LAS promoted aromatization as reflected by the large increase in aromatics selectivity. It was a cross-the-board selectivity increase for all aromatics, including BTX and A9+, however. The C4-HTI was only slightly weakened, implying that the Zn-LAS could also promote hydrogen transfer. The reversal of the alkanes and the aromatics selectivities suggested that Zn-LAS promoted hydrogen transfer less strongly than it promoted aromatization. This could also be inferred from the fact that the reduction of alkanes selectivity was mostly from the reduction of propane (from $28.9 \%$ on HZSM-5 to $14.3 \%$ on $\mathrm{Zn} / \mathrm{HZSM}-5)$. As Zn-LAS promoted more $\mathrm{P}$ aromatization, less
P was available for hydrogen transfer to propane. Similar observations had been reported in other works., ${ }^{\mathbf{2 , 9 , 1 3}}$

3.3.2 HZSM-5 vs. Si/HZSM-5. Si passivation of the HZSM-5 led to a significant $(48.5 \%)$ decrease in BAS, and a smaller (20\%) decrease in LAS (Table 5). The majority of the decreases could probably be attributed to the passivation of the acidic sites outside the zeolitic pores. The decrease in acidity, especially the decrease in Brønsted acid, appeared to be responsible for the large decreases of C4-HTI $(-39.5 \%)$ and alkanes selectivity($34.2 \%$ ) and the corresponding increase of alkenes selectivity. The passivation reduced A9+ selectivity sharply, indicating that most of the A9+ were made outside the zeolitic pores. On the other hand, the selectivity for BTX was essentially unchanged, implying that most of the BTX were formed inside the zeolitic pores.

3.3.3 Si/HZSM-5 vs. Zn/Si/HZSM-5. Table 6 shows that impregnation of $\mathrm{Zn}$ on $\mathrm{Si} / \mathrm{HZSM}-5$ further decreased BAS, but increased LAS. As BAS decreased more than LAS increased, total acid sites decreased with increasing $\mathrm{Zn}$ loading. However, impregnating $\mathrm{Zn}$ on $\mathrm{Si} / \mathrm{HZSM}-5$ did not show the same effects as impregnating Zn on HZSM-5. As discussed in Section 3.3.1, impregnating Zn on HZSM-5 raised the aromatics selectivity, reversing the alkanes and the aromatics selectivities. Impregnating $\mathrm{Zn}$ on $\mathrm{Si} / \mathrm{HZSM}-5$ neither raise the aromatics selectivity, in fact the aromatics and BTX selectivities remained largely unchanged, and nor reverse the alkanes and the aromatics selectivities, but it did raise the alkenes selectivity to the extent that it reversed the alkanes and the alkenes selectivities. The

Table 4 Product distribution, acid sites distribution and C4-HTI

\begin{tabular}{|c|c|c|c|c|c|c|c|c|c|}
\hline Catalyst & Aromatics & BTX & A9+ & Alkanes & Alkenes & LAS & BAS & $\begin{array}{l}\text { External acid } \\
\text { sites }(\%)\end{array}$ & C4-HTI \\
\hline HZSM-5 & 35.3 & 27.8 & 7.5 & 51.4 & 4.9 & 20 & 280 & 28 & 0.86 \\
\hline 1 wt $\%$ Zn/HZSM-5 & 48.4 & 38.3 & 10.1 & 33.0 & 6.1 & 108 & 123 & 25 & 0.81 \\
\hline
\end{tabular}

Table 5 Product distribution, acid sites distribution and C4-HTI

\begin{tabular}{|c|c|c|c|c|c|c|c|c|c|}
\hline \multirow[b]{2}{*}{ Catalyst } & \multicolumn{5}{|c|}{ Selectivity (wt\%) } & \multicolumn{2}{|c|}{$\begin{array}{l}\text { Amount of acid } \\
\text { sites }\left(\mu \mathrm{mol} \mathrm{g}^{-1}\right)\end{array}$} & \multirow{2}{*}{$\begin{array}{l}\text { External acid } \\
\text { sites }(\%)\end{array}$} & \multirow[b]{2}{*}{ C4-HTI } \\
\hline & Aromatics & BTX & A9+ & Alkanes & Alkenes & LAS & BAS & & \\
\hline HZSM-5 & 35.3 & 27.8 & 7.5 & 51.4 & 4.9 & 20 & 280 & 28 & 0.86 \\
\hline Si/HZSM-5 & 31.0 & 29.6 & 1.4 & 33.8 & 22.0 & 16 & 144 & 6 & 0.52 \\
\hline
\end{tabular}

Table 6 Product distribution, acid sites distribution and C4-HTI

\begin{tabular}{|c|c|c|c|c|c|c|c|c|c|}
\hline Catalyst & \multicolumn{5}{|c|}{ Selectivity (wt\%) } & \multicolumn{2}{|c|}{$\begin{array}{l}\text { Amount of } \\
\text { acid sites } \\
\left(\mu \mathrm{mol} \mathrm{g} \mathrm{g}^{-1}\right)\end{array}$} & $\begin{array}{l}\text { External acid } \\
\text { sites (\%) }\end{array}$ & C4-HTI \\
\hline Si/HZSM-5 & 31.0 & 29.6 & 1.4 & 33.8 & 22.0 & 16 & 144 & 6 & 0.52 \\
\hline $1 \mathrm{wt} \% \mathrm{Zn} / \mathrm{Si} / \mathrm{HZSM}-5$ & 30.1 & 28.5 & 1.6 & 21.2 & 35.6 & 52 & 106 & 3 & 0.27 \\
\hline
\end{tabular}




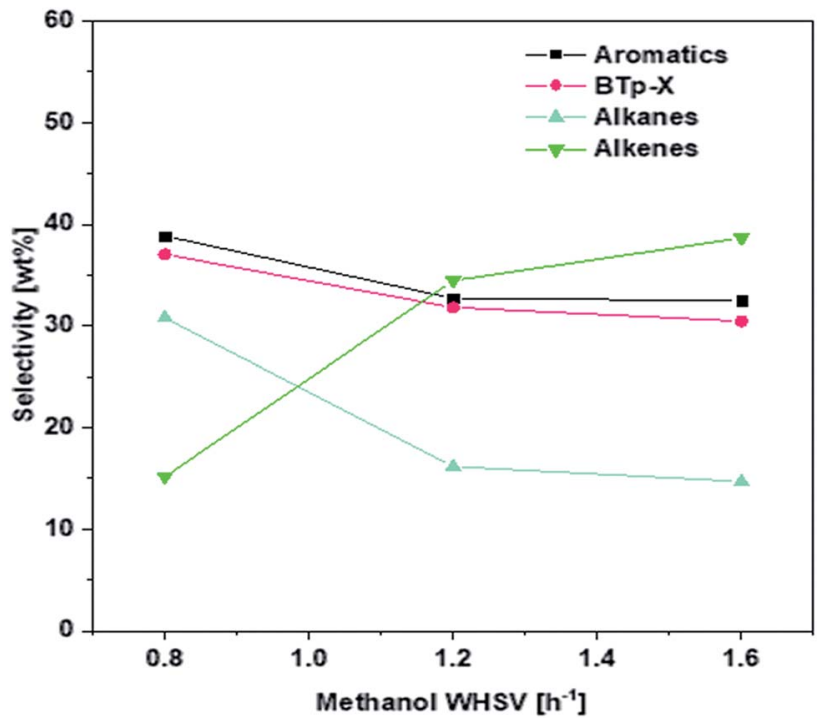

Fig. 8 Effect of WHSV on the product selectivity over $1.5 \mathrm{wt} \% \mathrm{Zn} / \mathrm{Si} /$ $\mathrm{HZSM}-5$. Reaction conditions: $0.1 \mathrm{MPa}, 430^{\circ} \mathrm{C}$, the data were obtained at $1 \mathrm{~h}$.

increase of alkenes appeared to be due to the reduction of hydrogen transfer as reflected by the corresponding reduction in alkanes selectivity and C4-HTI, which could all be traced back to the decrease of the BAS. On the other hand, although the amount of LAS were increasing, the extent of increasing seemed to be insufficient to raise the aromatics selectivity. The $\mathrm{Zn} / \mathrm{Si} /$ HZSM-5 catalysts had turned the systems into an alkenes-rich environment, but stopped short of converting these alkenes to aromatics, implying that the catalysts probably did not have the needed acidic sites to carry out more aromatization.

\subsection{Effect of WHSV on the product distribution}

The effect of WHSV on product distribution is shown in Fig. 8. It appears that product distribution was sensitive to the flowrate of methanol. As can be seen in Fig. 8, lower flow rates in the range of 0.8 WHSV favored the conversion of alkenes to aromatics via aromatization reaction and to alkanes via hydrogen transfer. On the other hand, higher WHSV seemed to hinder most significantly the hydrogen transfer reaction and more modestly the aromatization reaction, leading to a higher alkenes selectivity. Consequently, the $\mathrm{P} / \mathrm{BT}$ molar ratio could be tuned over a range from 0.4 to 1.7 using the $1.5 \mathrm{wt} \% \mathrm{Zn} / \mathrm{Si} /$ HZSM- 5 catalyst at $0.1 \mathrm{MPa}$ and $430{ }^{\circ} \mathrm{C}$ (Fig. 9). A P/BT molar ratio of 1.1 was achieved at a WHSV of $1.2 \mathrm{~h}^{-1}$. The combined selectivity of BT $p$-X and alkenes was $66.26 \mathrm{wt} \%$. The combined selectivities of $m-\mathrm{X}, o-\mathrm{X}, \mathrm{A} 9+$ and alkanes were only $16.8 \mathrm{wt} \%$.

\section{Conclusion}

This work investigated a series of catalysts, including HZSM-5, Si/HZSM-5, Zn/HZSM-5, and Zn/Si/HZSM-5 for a novel nonpetroleum route of methanol to phenol. It was found that the catalyst of $1.5 \mathrm{wt} \% \mathrm{Zn} / \mathrm{Si} / \mathrm{HZSM}-5$ was capable of converting methanol to a main product stream having a $\mathrm{P} / \mathrm{BT}$ molar ratio of unity, which would be an ideal feedstock for the manufacturing of phenol. The catalytic conversion also produced such relatively high-value byproducts as $p$-X and alkenes.

HZSM-5 produced mainly alkanes and aromatics, with the alkanes selectivity being much higher than the aromatics selectivity. The high alkanes selectivity probably was due to hydrogen transfer promoted by the large quantity of BAS found on HZSM-5.

Impregnating Zn on HZSM-5 reduced BAS substantially, but increased LAS also substantially. Alkanes and aromatics were still the main products, however, the aromatics selectivity had become much higher than the alkanes selectivity. The newly created Zn-LAS appeared to be promoting aromatization more strongly than promoting hydrogen transfer. Although the $\mathrm{Zn} /$ HZSM- 5 catalyst produced more aromatics, a good fraction of the aromatics were the relatively low-valued $m$-X, $o$-X, and A9+.
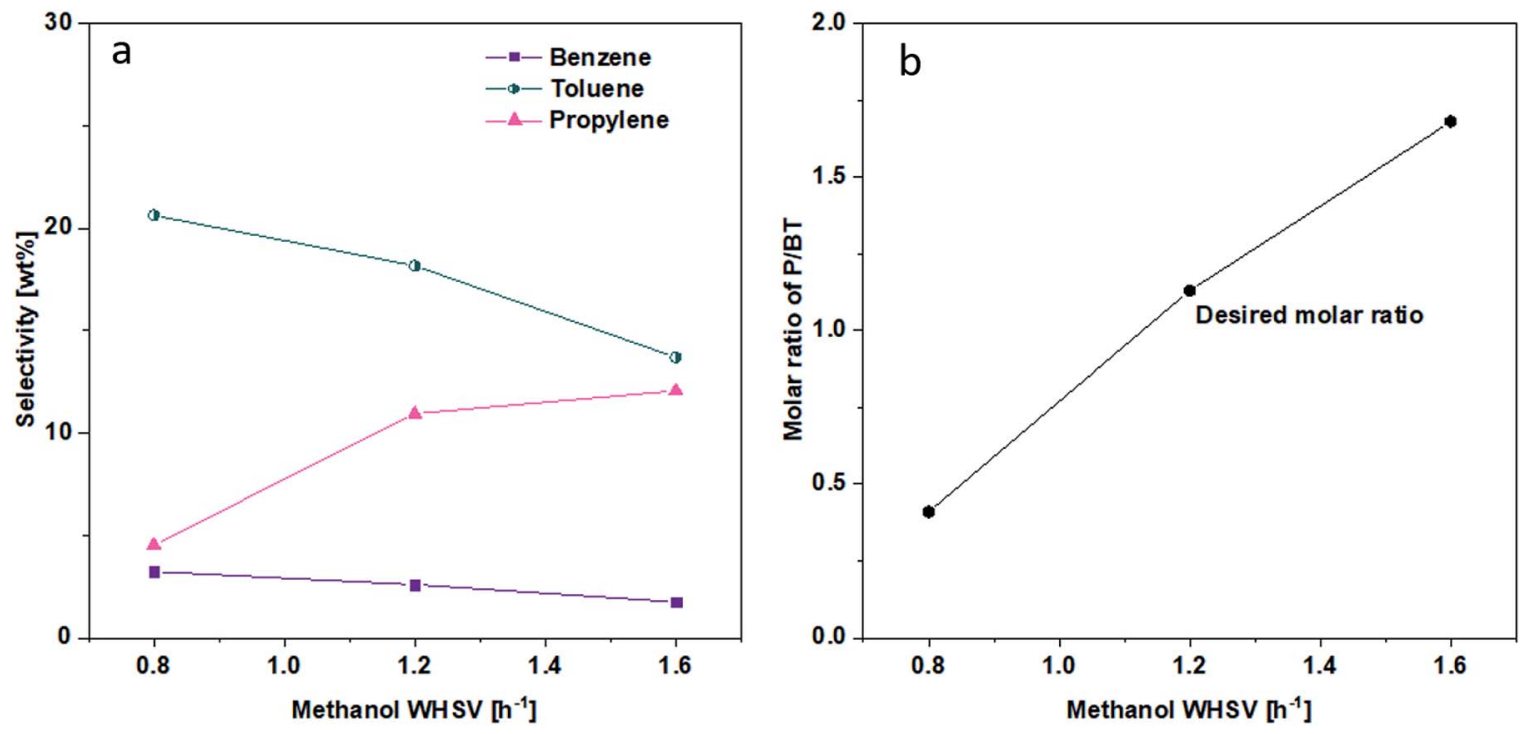

Fig. 9 Effect of WHSV on (a) B, T and P selectivity. (b) P/BT molar ratio. Reaction conditions; $0.1 \mathrm{MPa}, 430{ }^{\circ} \mathrm{C}$, the data were obtained at $1 \mathrm{~h}$. 
Silica deposition on HZSM-5 reduced BAS significantly. The majority of the reduction belonged to the BAS outside the zeolitic pores. Such passivation of external BAS appeared to do two shiftings, including a shifting of alkanes to alkenes and P, and a shifting amongst aromatics, in which the unwanted $m$-X, $o$-X, and $\mathrm{A} 9+$ were suppressed and the desired $p$-X and $\mathrm{T}$ were produced.

Impregnating $\mathrm{Zn}$ on Si/HZSM-5 reduced BAS further and created some LAS, with the net effects of decreasing total acid sites with increasing Zn loading. Such levels of catalyst acidity enabled the $\mathrm{Zn} / \mathrm{Si} / \mathrm{HZSM}-5$ catalysts to increase $\mathrm{P}$ selectivity without sacrificing the selectivities of $\mathrm{B}, \mathrm{T}$, and $p$-X. The exact control of selectivity can be achieved by adjusting WHSV. Thus, a P/BT molar ratio of near 1 along with good alkenes selectivity (34.5 wt\%), high $p$-X selectivity (11.1 wt\%) and purity ( $97.8 \mathrm{wt} \%)$ were achieved simultaneously at $0.1 \mathrm{MPa}, 430{ }^{\circ} \mathrm{C}$ and $1.2 \mathrm{~h}^{-1}$ WHSV on $1.5 \mathrm{wt} \% \mathrm{Zn} / \mathrm{Si} / \mathrm{HZSM}-5$.

Silica deposition, zinc impregnation, proper acidity adjustment, and process conditions were all essential for generating a product stream having a P/BT molar ratio of unity for the novel methanol to phenol process along with such high-value byproducts as $p$-X and alkenes.

\section{Appendix}

Table 7 Catalytic performance of Si/HZSM-5, Zn/HZSM-5, and Zn/Si/HZSM-5 catalysts

\begin{tabular}{|c|c|c|c|c|c|c|c|c|c|c|c|c|c|}
\hline & Catalysts & $\begin{array}{l}\text { Aromatics } \\
\text { (wt\%) }\end{array}$ & $\begin{array}{l}\text { B } \\
(\mathrm{wt} \%)\end{array}$ & $\begin{array}{l}\mathrm{T} \\
(\mathrm{wt} \%)\end{array}$ & $\begin{array}{l}X \\
(w t \%)\end{array}$ & $\begin{array}{l}p-\mathrm{X} / \mathrm{X} \\
(\mathrm{wt} \%)\end{array}$ & $\begin{array}{l}P \\
(w t \%)\end{array}$ & $\begin{array}{l}\text { Alkenes } \\
\text { (wt\%) }\end{array}$ & $\begin{array}{l}\text { Alkanes } \\
\text { (wt\%) }\end{array}$ & $\begin{array}{l}\mathrm{P} / \mathrm{BT} \\
\text { (Molar } \\
\text { ratio) }\end{array}$ & $\begin{array}{l}\text { Reaction } \\
\text { condition }\end{array}$ & $\begin{array}{l}\text { Sample } \\
\text { time (h) }\end{array}$ & Ref. \\
\hline \multirow[t]{4}{*}{$\begin{array}{l}\text { Zn- } \\
\text { modified } \\
\text { HZSM-5 } \\
\text { catalysts }\end{array}$} & $\begin{array}{l}5 \mathrm{wt} \% \mathrm{Zn} / \mathrm{HZSM}- \\
5,\left(\mathrm{HZSM}-5 \mathrm{SiO}_{2} /\right. \\
\left.\mathrm{Al}_{2} \mathrm{O}_{3}=38\right)\end{array}$ & $56.6(36.3)$ & $\begin{array}{l}2.0 \\
(2.3)\end{array}$ & $\begin{array}{l}17.7 \\
(12.0)\end{array}$ & $\begin{array}{l}24.4 \\
(13.9)\end{array}$ & $\begin{array}{l}24.2 \\
(23.7)\end{array}$ & $\begin{array}{l}2.2 \\
(1.2)\end{array}$ & $5.4(2.9)$ & $\begin{array}{l}23.3 \\
(43.7)\end{array}$ & $\begin{array}{l}0.2 \\
(0.2)\end{array}$ & 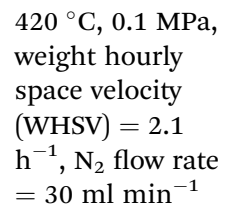 & 4 & 9 \\
\hline & $\begin{array}{l}1.5 \mathrm{wt} \% \mathrm{Zn} / \\
\mathrm{HZSM}-5,(\mathrm{HZSM}- \\
5 \mathrm{SiO}_{2} / \mathrm{Al}_{2} \mathrm{O}_{3}= \\
38)\end{array}$ & $50.9(27.7)$ & $\begin{array}{l}2.3 \\
(2.8)\end{array}$ & $\begin{array}{l}9.5 \\
(8.6)\end{array}$ & $\begin{array}{l}26.9 \\
(10.0)\end{array}$ & $\begin{array}{l}72.4 \\
(69.5)\end{array}$ & $\begin{array}{l}4.8 \\
(3.6)\end{array}$ & $\begin{array}{l}11.5 \\
(7.5)\end{array}$ & $\begin{array}{l}14.3 \\
(41.0)\end{array}$ & $\begin{array}{l}0.9 \\
(0.7)\end{array}$ & 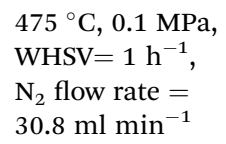 & 2.25 & 10 \\
\hline & $\begin{array}{l}1 \mathrm{wt} \% \mathrm{Zn} / \mathrm{HZSM}^{-} \\
5, \mathrm{HZSM}-5 \mathrm{SiO}_{2} / \\
\left.\mathrm{Al}_{2} \mathrm{O}_{3}=60\right)\end{array}$ & $49.5(24.8)$ & $\begin{array}{l}4.0 \\
(1.6)\end{array}$ & $\begin{array}{l}17.8 \\
(6.7)\end{array}$ & $\begin{array}{l}21.1 \\
(11.7)\end{array}$ & n.a. & $\begin{array}{l}14.4 \\
(22.1)\end{array}$ & $\begin{array}{l}31.1 \\
(39.5)\end{array}$ & $\begin{array}{l}10.3 \\
(27.9)\end{array}$ & $\begin{array}{l}1.4 \\
(5.6)\end{array}$ & $\begin{array}{l}450{ }^{\circ} \mathrm{C}, 0.1 \mathrm{MPa} \text {, } \\
\mathrm{WHSV}=\text { not } \\
\text { given, } \mathrm{N}_{2} \text { flow } \\
\text { rate }=88 \\
\mathrm{ml} \mathrm{min}^{-1}\end{array}$ & 12 & 11 \\
\hline & $\begin{array}{l}1 \mathrm{wt} \% \mathrm{Zn} / \mathrm{HZSM}^{-} \\
5,\left(\mathrm{HZSM}-5 \mathrm{SiO}_{2} /\right. \\
\left.\mathrm{Al}_{2} \mathrm{O}_{3}=30\right)\end{array}$ & $65.9(38.4)$ & $\begin{array}{l}4.9 \\
(2.1)\end{array}$ & $\begin{array}{l}14.9 \\
(5.6)\end{array}$ & $\begin{array}{l}25.9 \\
(14.1)\end{array}$ & $\begin{array}{l}24.1 \\
(23.5)\end{array}$ & $\begin{array}{l}2.1 \\
(2.3)\end{array}$ & $4.6(5.4)$ & $\begin{array}{l}26.0 \\
(48.8)\end{array}$ & $\begin{array}{l}0.2 \\
(0.6)\end{array}$ & $\begin{array}{l}460{ }^{\circ} \mathrm{C}, 0.1 \mathrm{MPa}, \\
\mathrm{WHSV}=1 \mathrm{~h}^{-1}, \\
\mathrm{~N}_{2} \text { flow rate }=80 \\
\mathrm{ml} \mathrm{min}^{-1}\end{array}$ & 0.5 & 13 \\
\hline \multirow[t]{3}{*}{$\begin{array}{l}\text { Silica } \\
\text { deposited } \\
\text { HZSM-5 } \\
\text { catalysts }\end{array}$} & $\begin{array}{l}\mathrm{SiO}_{2} / \mathrm{HZSM}-5 \\
\left(\mathrm{HZSM}-5 \mathrm{SiO}_{2} /\right. \\
\left.\mathrm{Al}_{2} \mathrm{O}_{3}=30\right)\end{array}$ & $33.8(38.4)$ & $\begin{array}{l}8.3 \\
(2.1)\end{array}$ & $\begin{array}{l}10.2 \\
(5.6)\end{array}$ & $\begin{array}{l}12.8 \\
(14.1)\end{array}$ & $\begin{array}{l}97.3 \\
(23.5)\end{array}$ & $\begin{array}{l}4.3 \\
(2.3)\end{array}$ & $8.9(5.4)$ & $\begin{array}{l}49.7 \\
(48.8)\end{array}$ & $\begin{array}{l}0.5 \\
(0.6)\end{array}$ & $\begin{array}{l}460{ }^{\circ} \mathrm{C}, 0.1 \mathrm{MPa}, \\
\mathrm{WHSV}=1 \mathrm{~h}^{-1}, \\
\mathrm{~N}_{2} \text { flow rate }=80 \\
\mathrm{ml} \mathrm{min}^{-1}\end{array}$ & 0.5 & 13 \\
\hline & 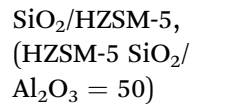 & $27.4(37.5)$ & $\begin{array}{l}7.0 \\
(7.9)\end{array}$ & $\begin{array}{l}8.9 \\
(9.5)\end{array}$ & $\begin{array}{l}9.5 \\
(12.5)\end{array}$ & $\begin{array}{l}98.1 \\
(24.0)\end{array}$ & $\begin{array}{l}14.0 \\
(0.7)\end{array}$ & $\begin{array}{l}36.3 \\
(2.3)\end{array}$ & $\begin{array}{l}34.4 \\
(59.5)\end{array}$ & $\begin{array}{l}1.8 \\
(0.1)\end{array}$ & $\begin{array}{l}400^{\circ} \mathrm{C}, 0.1 \mathrm{MPa}, \\
\text { WHSV }=1 \mathrm{~h}^{-1}, \\
\mathrm{~N}_{2} \text { flow rate }=40\end{array}$ & 0.5 & 16 \\
\hline & 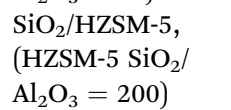 & $23.1(35.4)$ & $\begin{array}{l}5.9 \\
(8.3)\end{array}$ & $\begin{array}{l}7.0 \\
(9.8)\end{array}$ & $\begin{array}{l}8.8 \\
(12.3)\end{array}$ & $\begin{array}{l}96.3 \\
(24.2)\end{array}$ & $\begin{array}{l}28.2 \\
(6.5)\end{array}$ & $\begin{array}{l}55.4 \\
(11.9)\end{array}$ & $\begin{array}{l}18.3 \\
(50.7)\end{array}$ & $\begin{array}{l}4.4 \\
(0.7)\end{array}$ & $\mathrm{ml} \min ^{-1}$ & & \\
\hline \multirow[t]{3}{*}{$\begin{array}{l}\text { Zn- } \\
\text { modified } \\
\mathrm{Si} / \\
\text { HZSM-5 }\end{array}$} & $\begin{array}{l}0.73 \text { wt } \% \mathrm{Zn} / \\
\mathrm{HZSM}-5 / \mathrm{SiO}_{2} \\
\left(\mathrm{Si} / \mathrm{HZSM}-5 \mathrm{SiO}_{2} /\right. \\
\left.\mathrm{Al}_{2} \mathrm{O}_{3}=28\right)\end{array}$ & $36.6(27.4)$ & $\begin{array}{l}0.8 \\
(1.2)\end{array}$ & $\begin{array}{l}11.0 \\
(8.1)\end{array}$ & $\begin{array}{l}18.8 \\
(12.9)\end{array}$ & $\begin{array}{l}94.8 \\
(93.2)\end{array}$ & n.a. & n.a. & n.a. & n.a. & $\begin{array}{l}450{ }^{\circ} \mathrm{C}, 0.1 \mathrm{MPa} \\
\mathrm{WHSV}=2.3 \mathrm{~h}^{-1}\end{array}$ & 2 & 12 \\
\hline & $\begin{array}{l}1 \mathrm{wt} \% \mathrm{Zn} / \mathrm{Si} / \\
\mathrm{HZSM}-5,(\mathrm{Si} / \\
\mathrm{HZSM}-5 \mathrm{SiO}_{2} / \\
\left.\mathrm{Al}_{2} \mathrm{O}_{3}=30\right)\end{array}$ & $59.8(33.8)$ & $\begin{array}{l}14.2 \\
(8.3)\end{array}$ & $\begin{array}{l}18.6 \\
(10.2)\end{array}$ & $\begin{array}{l}22.7 \\
(12.8)\end{array}$ & $\begin{array}{l}97.8 \\
(97.3)\end{array}$ & $\begin{array}{l}3.4 \\
(4.3)\end{array}$ & $6.7(8.9)$ & $\begin{array}{l}27.7 \\
(49.7)\end{array}$ & $\begin{array}{l}0.2 \\
(0.5)\end{array}$ & $\begin{array}{l}460{ }^{\circ} \mathrm{C}, 0.1 \mathrm{MPa}, \\
\mathrm{WHSV}=1 \mathrm{~h}^{-1}, \\
\mathrm{~N}_{2} \text { flow rate }=80 \\
\mathrm{ml} \mathrm{min}^{-1}\end{array}$ & 0.5 & 13 \\
\hline & $\begin{array}{l}3 \mathrm{wt} \% \mathrm{ZnO} / \mathrm{Si} / \\
\mathrm{HZSM}-5(\mathrm{Si} / \\
\mathrm{HZSM}-5 \mathrm{SiO}_{2} / \\
\left.\mathrm{Al}_{2} \mathrm{O}_{3}=25\right)\end{array}$ & 28 (n.a.) & n.a. & n.a. & n.a & $\begin{array}{l}86.6 \\
\text { (n.a.) }\end{array}$ & $\begin{array}{l}8.8 \\
\text { (n.a.) }\end{array}$ & n.a. & n.a. & n.a. & $\begin{array}{l}475{ }^{\circ} \mathrm{C}, 0.1 \mathrm{MPa}, \\
\mathrm{WHSV}=0.79 \\
\mathrm{~h}^{-1}\end{array}$ & 0.5 & 14 \\
\hline
\end{tabular}




\section{Conflicts of interest}

There are no conflicts to declare.

\section{Acknowledgements}

This work was financially supported by a ChangChun Group, Taiwan and the Ministry of Science and Technology (MOST 1042622-8-007-001).

\section{References}

1 T. F. Degnan Jr, C. M. Smith and C. R. Venkat, Appl. Catal., A, 2001, 221, 283-294.

2 Y. Jia, J. Wang, K. Zhang, W. Feng, S. Liu, C. Ding and P. Liu, J. Energy Chem., 2017, 26, 540-548.

3 J. Zhang, X. Zhu, S. Zhang, M. Cheng, M. Yu, G. Wang and C. Li, Catal. Sci. Technol., 2019, 9, 316-326.

4 Y. Inoue, K. Nakashiro and Y. Ono, Microporous Mater., 1995, 4, 379-383.

5 J. A. Lopez-Sanchez, M. Conte, P. Landon, W. Zhou, J. K. Bartley, S. H. Taylor, A. F. Carley, C. J. Kiely, K. Khalid and G. J. Hutchings, Catal. Lett., 2012, 142, 1049-1056.

6 J. Li, C. Hu, K. Tong, H. Xiang, Z. Zhu and Z. Hu, RSC Adv., 2014, 4, 44377-44385.

7 Z. Zhang, B. Liu, F. Liu, Y. Zhao and T. Xiao, Catal. Today, 2018, 317, 21-28.

8 X. Wang, J. Zhang, T. Zhang, H. Xiao, F. Song, Y. Han and Y. Tan, RSC Adv., 2016, 6, 23428-23437.

9 Y. Zhang, Y. Qu, D. Wang, X. C. Zeng and J. Wang, Ind. Eng. Chem. Res., 2017, 56, 12508-12519.

10 C. Xu, B. Jiang, Z. Liao, J. Wang, Z. Huang and Y. Yang, RSC Adv., 2017, 7, 10729-10736.
11 M. Conte, J. A. Lopez-Sanchez, Q. He, D. J. Morgan, Y. Ryabenkova, J. K. Bartley, A. F. Carley, S. H. Taylor, C. J. Kiely and K. Khalid, Catal. Sci. Technol., 2012, 2, 105112.

12 D. Pan, X. Song, X. Yang, L. Gao, R. Wei, J. Zhang and G. Xiao, Appl. Catal., A, 2018, 557, 15-24.

13 J. Li, K. Tong, Z. Xi, Y. Yuan, Z. Hu and Z. Zhu, Catal. Sci. Technol., 2016, 6, 4802-4813.

14 Q. Hu, X. Huang, Y. Cui, T. Luo, X. Tang, T. Wang, W. Qian and F. Wei, RSC Adv., 2017, 7, 28940-28944.

15 L. Sun, Y. Wang, H. Chen, C. Sun, F. Meng, F. Gao and X. Wang, Catal. Today, 2018, 316, 91-98.

16 J. Li, Y. Wang, W. Jia, Z. Xi, H. Chen, Z. Zhu and Z. Hu, J. Energy Chem., 2014, 23, 771-780.

17 A. F. Silva, A. Fernandes, P. Neves, M. M. Antunes, S. M. Rocha, M. F. Ribeiro, C. M. Silva and A. A. Valente, ChemCatChem, 2018, 10, 2741-2754.

18 Y. Jia, J. Wang, K. Zhang, W. Feng, S. Liu, C. Ding and P. Liu, Microporous Mesoporous Mater., 2017, 247, 103-115.

19 M. Bjørgen, F. Joensen, M. S. Holm, U. Olsbye, K.-P. Lillerud and S. Svelle, Appl. Catal., A, 2008, 345, 43-50.

20 T. Fu, H. Zhou and Z. Li, Catal. Lett., 2016, 146, 1973-1983. 21 G. Q. Zhang, T. Bai, T. F. Chen, W. T. Fan and X. Zhang, Ind. Eng. Chem. Res., 2014, 53, 14932-14940.

22 S.-H. Zhang, Z.-X. Gao, S.-J. Qing, S.-Y. Liu and Y. Qiao, Chem. Pap., 2014, 68, 1187-1193.

23 J.-y. WANG, W.-h. LI and J.-x. HU, J. Fuel Chem. Technol., 2009, 37, 607-612.

24 Y. Bi, Y. Wang, X. Chen, Z. Yu and L. Xu, Chin. J. Catal., 2014, 35, 1740-1751.

25 X. Niu, J. Gao, Q. Miao, M. Dong, G. Wang, W. Fan, Z. Qin and J. Wang, Microporous Mesoporous Mater., 2014, 197, 252-261. 